\title{
Identification of Tribological Research and Development Needs for Lubrication of Advanced Heat Engines
}

September 1985

Prepared for the U.S. Department of Energy under Contract DE-AC06-76RLO 1830

Pacific Northwest Laboratory Operated for the U.S. Department of Energy by Battelle Memorial Institute 


\title{
DISCLAIMER
}

This report was prepared as an account of work sponsored by an agency of the United States Government. Neither the United States Government nor any agency thereof, nor any of their employees, makes any warranty, express or implied, or assumes any legal liability or responsibility for the accuracy, completeness, or usefulness of any information, apparatus, product, or process disclosed, or represents that its use would not infringe privately owned rights. Reference herein to any specific commercial product, process, or service by trade name, trademark, manufacturer, or otherwise, does not necessarily constitute or imply its endorsement, recommendation, or favoring by the United States Government or any agency thereof. The views and opinions of authors expressed herein do not necessarily state or reflect those of the United States Government or any agency thereof.

\author{
PACIFIC NORTHWEST LABORATORY \\ operated by \\ BATTELLE \\ for the \\ UNITED STATES DEPARTMENT OF ENERGY \\ under Contract DE-AC06-76RLO 1830
}

\begin{tabular}{|c|c|}
\hline \multicolumn{2}{|c|}{ Printed in the United States of America } \\
\hline \multicolumn{2}{|c|}{ Available from } \\
\hline \multicolumn{2}{|c|}{ National Technical Information Service } \\
\hline \multicolumn{2}{|c|}{ United States Department of Commerce } \\
\hline 5285 & \\
\hline \multicolumn{2}{|c|}{ Springfield, Virginia 22161} \\
\hline \multirow{2}{*}{\multicolumn{2}{|c|}{$\begin{array}{l}\text { NTIS Price Codes } \\
\text { Microfiche A01 }\end{array}$}} \\
\hline & \\
\hline \multicolumn{2}{|c|}{ Printed Copy } \\
\hline & Price \\
\hline Pages & Codes \\
\hline 001-025 & $\mathrm{A} 02$ \\
\hline 026-050 & $\mathrm{A} 03$ \\
\hline 051-075 & A04 \\
\hline 076-100 & A05 \\
\hline $101-125$ & $\mathrm{~A} 06$ \\
\hline $126-150$ & A07 \\
\hline $151-175$ & $\mathrm{~A} 08$ \\
\hline $176-200$ & $A 09$ \\
\hline $201-225$ & A010 \\
\hline 226-250 & A011 \\
\hline $251-275$ & A012 \\
\hline $276-300$ & A013 \\
\hline
\end{tabular}


IDENTIFICATION OF TRIBOLOGICAL RESEARCH AND DEVEL.OPMENT NEEDS FOR LUBRICATION OF ADVANCED HEAT ENGINES

L. L. Fehrenbacher Technology Assessment \& Transfer, Inc.

T. M. Levinson DOE/ECIT Program Manager

September 1985

Prepared for

Energy Conversion and Technologies Utilization Division Office of Energy Systems Research Conservation and Renewable Energy U.S. Department of Energy under Contract DE-AC06-76RLO 1830

Pacific Northwest Laboratory Richland, Washington 99352 
Experts estimate that in 1978 over four quadrillion Btu of energy were lost in the United States because of simple friction and wear--enough energy to supply New York City for an entire year. This translates to a $\$ 20$ billion loss, based on oil prices of about $\$ 30$ per barrel. (a) Because of the enormity of this energy loss, the Energy Conversion and Utilization Technologies (ECUT) Program in the U.S. Department of Energy (DOE) initiated a program in 1983 to study tribology--the science of friction and wear--to learn more about the causes of these energy losses (or tribological "sinks") and how to reduce them.

The ECUT Program itself was started in 1980 to encourage research to improve energy conversion and utilization efficiency. The enormous energy loss in tribological sinks has been targeted by the ECUT program as having significant potential for energy conservation. One goal of the ECUT Tribology Program is to reduce these energy losses by developing improved lubricants and more durable materials.

To support initial Tribology Program planning, ECUT conducted six surveys to gather three types of information about the current tribology problem in the U.S.:

1. The identification of typical industrial sinks

2. A survey of current U.S. Government tribology projects

3. The identification of tribology R\&D needs based on industry perceptions.

The six ECUT-sponsored surveys are listed in Table ES.1. Each survey is being published as a separate volume with its own summary. This executive summary, which also appears in each of the six volumes, presents an overview of results from the six surveys and their implications for energy conservation. The results of these six surveys and their implications for energy conservation are presented in this summary. These results will be used to support further research planning for the ECUT Tribology Progran.
TABLE ES.1. ECUT Surveys Reviewed in this Summary

1. A Review of Tribological Sinks in Six Major Industries. Imhoff, et a1. PNL-5535, Pacific Northwest Laboratory, Richland, Washington.

2. Reduction in Tribological Energy Losses in the Transportation and Electric Utilities Sectors. Pinkus and Wilcock, Mechanical Technology Incorporated. PNL-5536, Pacific Northwest Laboratory, Richland, Washington.

3. Identification of Tribological Research and Development Needs for Lubrication of Advanced Heat Engines. Fehrenbacher, Technology Assessment and Transfer, Incorporated. PNL-5537, Pacific Northwest Laboratory, Richland, Washington.

4. Eneray Conservation Potential of Surface Modification Technologies. Le Khac, DHR, Inc. PNL-5538, Pacific Northwest Laboratory, Richland, Washington.

5. Assessment of Government Tribology Programs. Peterson, Wear Sciences Corporation. PNL-5539, Pacific Northwest Laboratory, Richland, Washington.

6. Assessment of Industrial Attitudes Toward Generic Research Needs in Tribology. Sibley and Zlotnick, Tribology Consultants Incorporated. PNL -5540 , Pacific Northwest Laboratory, Richland, Washington.

IDENTIFYING TYPICAL TRIBOLOGICAL SINKS AND MECHANISMS

ECUT's first step in collecting information about tribology was to identify significant tribological sinks and mechanisms. This information was needed to focus research on key technological problems. Because the industry, transportation, and utilities sectors account for most of the

(a) Calculations in this summary are based on a $\$ 30$ figure. 
energy consumed in the U.S., ECUT concentrated first on the tribological energy sinks and mechanisms found in these three sectors. The report by Imhoff, et al., describes the most important tribological sinks typically found in industry, and the report by Pinkus and Wilcock describes tribological energy losses in the transportation and utilities sectors. Two specific studies assessed tribological problems in the metalworking industry and in the advanced diesel engine.

To identify areas in which tribology has a significant impact, the authors examined the energy consumed, the fuels used, and the primary products and processes found in the transportation; industrial, and utilities sectors. Once energy losses were identified, their magnitude was estimated. The estimates include both friction losses (direct losses) and material wear losses (indirect losses). The authors also estimated the energy savings potential in each sector and recommended some specific R\&D programs to help achieve these energy savings.

\section{The Industrial Sector}

Tribological energy losses are pervasive throughout industry. Because reviewing all industries and industrial processes in detail would be impossible, the Imhoff, et al. survey, instead chose six representative industries (Mining, Agriculture, Primary Metals, Chemicals/Refining, Pulp and Paper, and Food Processing) that appeared to have the most significant tribological sinks and energy losses. These industries were selected because of their 1) major, nonthemal energy streams (such as machine drives); 2) high material wear rates and friction; 3) significant material transportation/alteration processes; and 4) total energy use.

The study identified important tribological sinks in each selected industry, based on both friction and material wear energy losses and on the tribological mechanisins and materials involved. Figure ES.1 and Table ES.2 show the key results for each of the six industries.

The first conclusion from this study confirmed earlier claims that losses from material wear are greater than energy losses from friction; the wear losses in five of the industries were found to be more thap twice as large as the friction losses. (a) The study also concluded that reducing material wear rates to improve equipment life

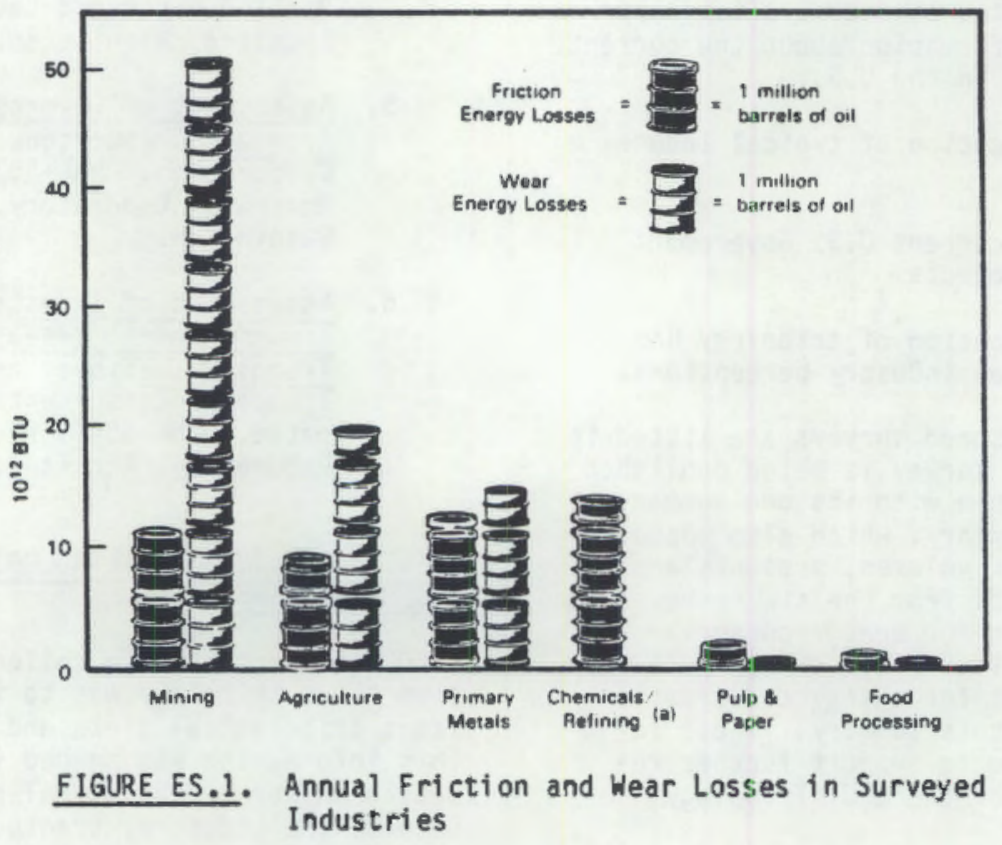

(a) These five industries had estimates of both friction and material wear losses; the sixth, Chemicals/Refining, did not have estimates of wear losses. 
TABLE ES.2. Primary Mechanisms in Friction Energy Losses and Principal Materials Involved in Wear Energy Losses

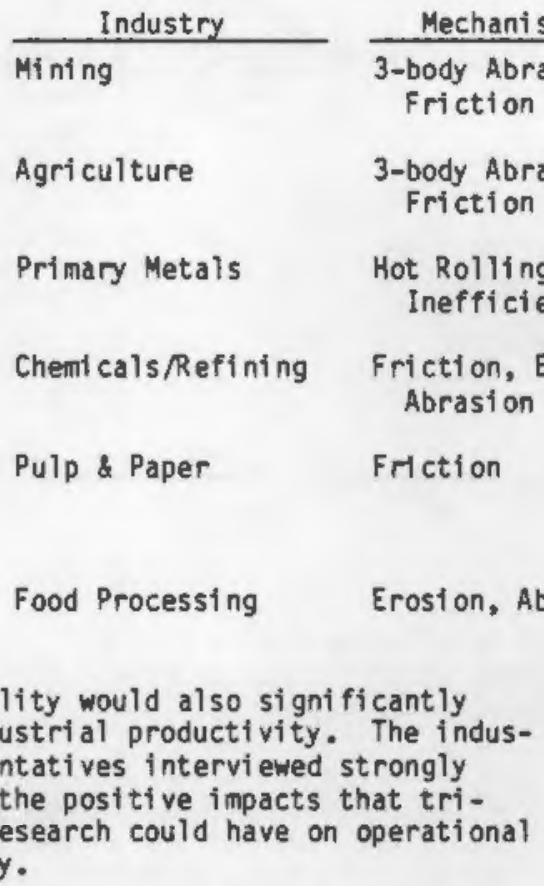

Tribology in the Metalworking Industry

In addition to the general review of tribological sinks in industry, ECUT sponsored a more specific study of tribology in the metalworking industry by Le Khac at $D H R$, Inc. The study estimated the energy conservation potential of using advanced surface modification technologies in this industry. These surface modification technologies are thermal, chemical, or mechanical treatments that reduce friction and wear at a material's surface without changing its bulk properties. The advanced surface modification technologies considered were ion implantation, laser surface hardening, electron beam surface hardening, and wearresistant coating deposition. The author studied 70 percent of the metal-forming and metal-cutting machines used in the United States (except those associated with primary metals processing), identified tribological mechanisms, and estimated friction and wear energy losses. Potential energy savings from using surface-modified tools were also estimated.

The metal-forming machines studied were punches, presses and forges, and the metalcutting machines studied were turning,
Materials

Iron, Steel \& alloys,

Alumi num, Rubber

Steel, Rubber, Lubricants

Steel \& alloys

Not studied

Steel \& alloys, ChromíumMolybdenum alloys Grinding stones

Steel alloys drilling, milling, broaching, and sawing machines. Models were developed to estimate friction and wear energy losses and potential savings. The friction losses were estimated by adding friction losses at the motor drive system and at the tool-workpiece interface. Estimates of energy consumption were based on standard operating conditions (known friction coefficients, total working time, etc.) The indi rect losses from wear were estimated based on the replacement costs of all metalworking tools used and discarded in one year.

Based on actual experimental or production data, the author estimated that the friction losses in all U.S. getalworking machines amount to $20.2 \times 10^{12} \mathrm{Btu}$ per jear, or $\$ 104.5$ million. Of this energy loss, $1.8 \times$ $10^{12}$ Btu per year, or $9 \%$, could be saved using surface modification technologies to reduce friction. The wear loss was estimated to be $7.7 \times 10^{12}$ Btu per year. (a) Possible energy savings using surface modification technologies to reduce wear could conserve $5.5 \times 10^{12}$ Btu per year, or $71 \%$.

Finally, the author estimated that tribological energy losses in all U,S. metalworking machines total $27.9 \times 10^{12} \mathrm{Btu}$, equivalent to $4.8 \mathrm{milli}$ on barrels of oil or $\$ 144$ million annually. More than a quarter of this loss could be saved using surface modification technologies to reduce friction and wear. These results are shown in Figure ES.2.

(a) Using 19.2 million Btu per ton as the embodied energy in steels. 


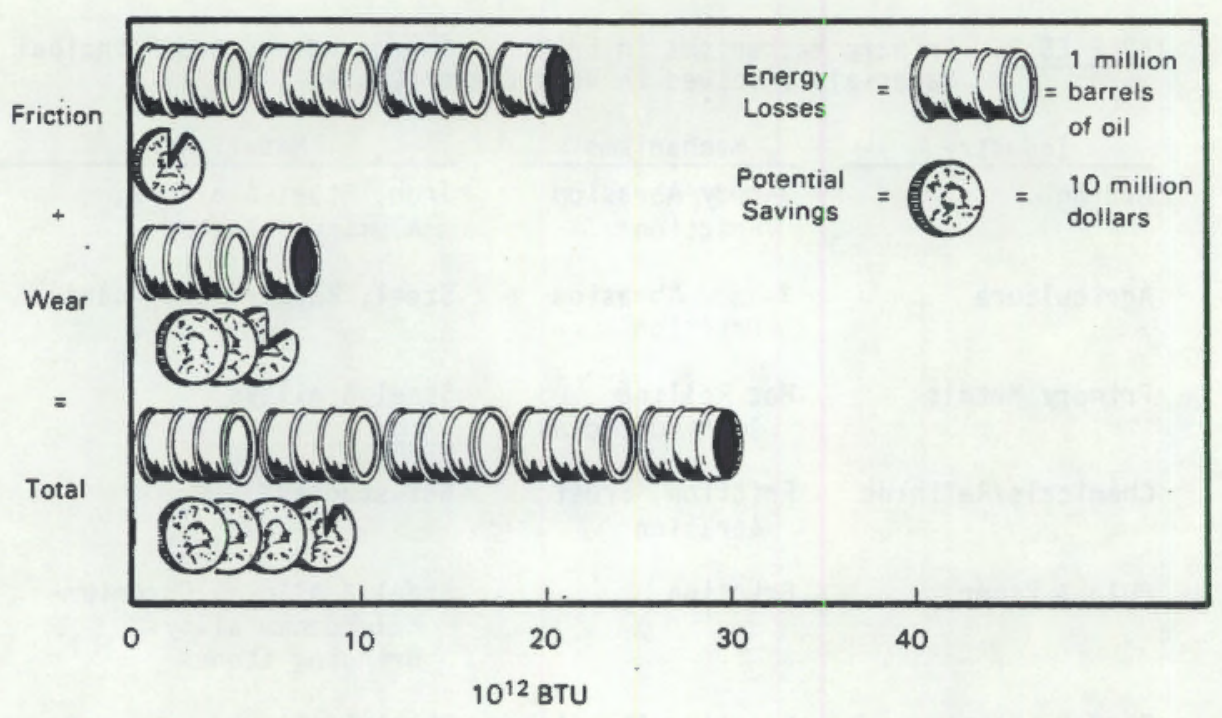

FIGURE ES.2. Annual Friction and Wear Energy Losses in the Metalworking Industry, and Potential Savings from Surface Modification Technologies

\section{The Transportation Sector}

The transportation sector is important both in terms of its energy consumption (26\% of tota] U.S. annual energy consumption, or $19 \times 10^{15} \mathrm{Btu}$, equivalent to $\$ 98$ billion), and because of the high level of tribological losses. The Pinkus and Wilcock study primarily focused on the highway fleets (passenger cars, buses and trucks), which consume $77 \%$ of the total energy used in the transportation sector. The survey primarily addressed the conventional Otto cycle engine. However, other concepts were also considered, such as the adiabatic diesel, the gas turbine, and the Stirling engine; in addition, the Fehrenbacher report evaluated tribological activity in advanced diesel engines.

Figure ES.3 shows the principal automotive tmbological sinks and the estimated energy savings. The principal automotive energy sinks are caused by the mechanical inefficiency of the engines and drive trains; most of the energy losses are due to friction.

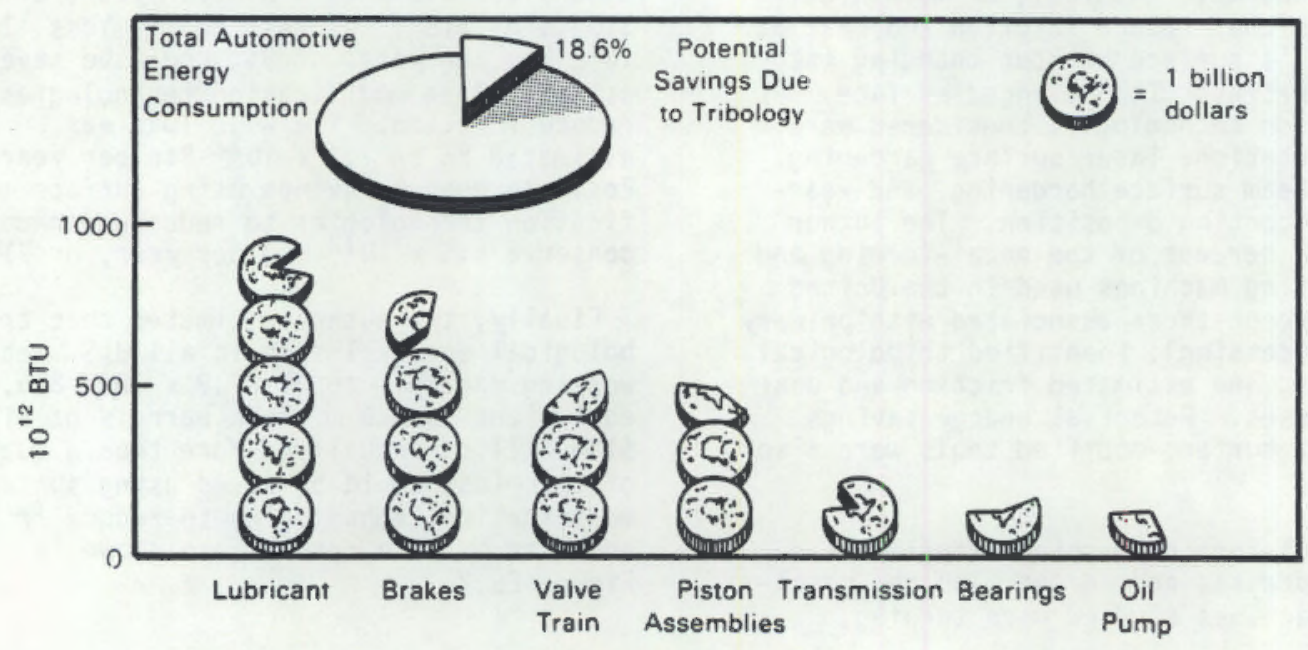

FIGURE ES.3. Potential Energy Savings Per Year for the Conventional Engine (Based on hi ghway fleet size in 1976) 
The survey by Pinkus and Wilcock revealed several tribological areas of particular concern for conventional engines, such as the piston ring assembly and the long-range effect of low-viscosity oil on engine wear. As shown in Figure ES.3, tribological improvements could save $18.6 \%$ of the total annual energy consumed by automobiles, or $\$ 14.3$ billion.

Research on conventional engines often applies to unconventional engínes as well. Except for the adiabatic diesel, the energy savings possible from tribological improvements to unconventional engines are less significant than those of the conventional otto cycle engine. The major problems in unconventional engines are related to hightemperature tribological problens. Introducing adiabatic and minimum friction engines into the bus and truck fleets of the U.S. could save up to $2.9 \%$ of total U.S. energy consumption.

This survey also revealed the difficulties with devising adequate performance tests to quantify energy losses and evaluate new designs and products. Laboratory tests that accurately reflect real-world conditions are badly needed. The ability to test entire systems is vital, since tribological energy losses are often caused by complex interactions between all the components of a system.

\section{Advanced Diesel Engines}

Because of the great potential for energy savings, the ECUT study by Fehrenbacher examined the lubrication of advanced diesel engines in detail. The efficiency of these engines could be improved by about 10\%; however, higher operating temperatures $\left(1000^{\circ} \mathrm{F}\right.$ and higher in the upper cylinder area) are requiled to reach this greater efficiency. As a result, the primary development challenge for these engines concerns friction, wear, and lubrication of the upper cylinder region. In fact, tribological advancements in these areas are essential if diesel engine performance and durability goals are to be reached. This study assessed these vital tribological concerns in both current and future technologies and recommended tribology R\&D topics for further advanced engi ne development.

Both the mechanical design of the upper cylinder and the chemical effects of lubricants and fuel determine the friction and wear characteristics of the upper cylinder region. These two factors interact in a complex and sometimes synergistic manner. The geometry of the piston, piston ring, and cylinder di rectly affect the rate and nature of deposit formation, oil consumption, and friction. Efforts have been made to opti mize the upper cylinder geometry in current diesel engine technology; this will also be a critical area in future developments. However, problems with upper cylinder deposits, bore polishing, and oil consumption still exist. This study indicates that these problems are caused by the chemical interactions between upper cylinder materials, oil degradation products, and fuel combustion by-products. Therefore, lubricants, oil degradation rates, and mechanisms will continue to be important research areas.

Although a great deal of research has been conducted on liquid lubricants, in most cases the lubricants have been tested without considering the tribological factors specific to the upper cylinder. Since the lubricants interact with the materials and environment of the upper cylinder, they must be developed and tested under similar conditions.

The ECUT study also pointed out that future advanced engine concepts will require ceramic upper cylinder materials able to withstand the higher operating temperatures. New lubricants will have to be developed, and solid lubricants are likely to play a major role. A major research effort will be needed in this area; again, the research must be conducted on a total system basis to be most effective.

The study concluded that many problems with current diesel engines will continue to exist in advanced diesel engines. Tribological problems in the upper cylinder region will be most critical in terms of engine performance and wear. Lubricant R\&D is still a major research area in current technology, but total system materials and design considerations should be emphasized. Advanced diesel concepts will requi re new design approaches, but the tribology of the upper cylinder region will still be critical and may even be the limiting factor in achieving higher engine efficiencies. Extensive materials R\&D will be required for advanced designs as well, especially in ceramics, ceramic composites and solid lubricants.

\section{The Utilities Sector}

The utilities sector was also reviewed for significant tribology sinks. This sector accounts for roughly $28 \%$ of total U.S. energy consumption. ECUT's revi ew revealed that tribological improvements in efficiency and reliability could save 2.3\% of the total energy annually consumed by utilities, or about $\$ 2.5$ billion. As in the transportation sector, efficiency is a major factor. 
However, reliability (especially in generating units) is just as important for energy conservation.

The data used in these studies were primarily for the utilities' power plants. The average power plant operates at an efficiency (output energy/input energy) between 30 and $40 \%$. Mechanical losses account for 17-26\% of the total energy used. Reliability problems that lead to generator shutdown requi re using standby equipment, which generally has less efficient fuel consumption. This causes losses both in terms of fuel economy, and revenue and labor costs. Tribological problems are estimated to cause as much as $5 \%$ of the reliability problems that require shutdown. Furthermore, tribology-caused shutdowns increase with the size of the power generating unit.

The ECUT survey found several tribological areas with significant energy savings potential, including gas path leakage, seals, and bearings on both the main turbine generator and on the various accessories. Different forms of bearing and lubricant problems (contami nated oils, pump problems, etc.) and vibrations are the leading causes of the plant shutdowns.

Figure ES.4 summarizes potential savings from improving tribological problems in the electric utilities. For accessories, the major concern is sealing problems with feedwater pumps. Friction and wear are implicated in much of the seal and bearing losses. The major problems identified in this study will require research on lubrication theory and advanced materials and coatings developments.

\section{CURRENT U.S. GOVERNMENT PROGRAMS}

The second part of ECUT's information collecting efforts involved identifying tribology R\&D currently being sponsored or conducted by the U.S. Government. This information was needed to avoid duplicating existing research and to locate those areas that need more research support. The Peterson study identified 215 current projects sponsored by 21 different. government organizations. The study classified these projects by subject, objective, energy conservation relevance, type of research, phenomena and variables being investigated, materials, and applications. The principal government sponsors include the Department of Defense (DOD), the National Aeronautics and Space Administration (NASA), National Science Foundation (NSF), National Bureau of Standards (NBS), and DOE.

The study located these tribology projects initially by using information from literature searches. Data bases used included the Smithsonian Science Information Exchange, the Defense Technical Information Center's Research and Technology Work Unit Information System, and the Materials Science Abstracts of the National Technical Information Service (NTIS). The study located a

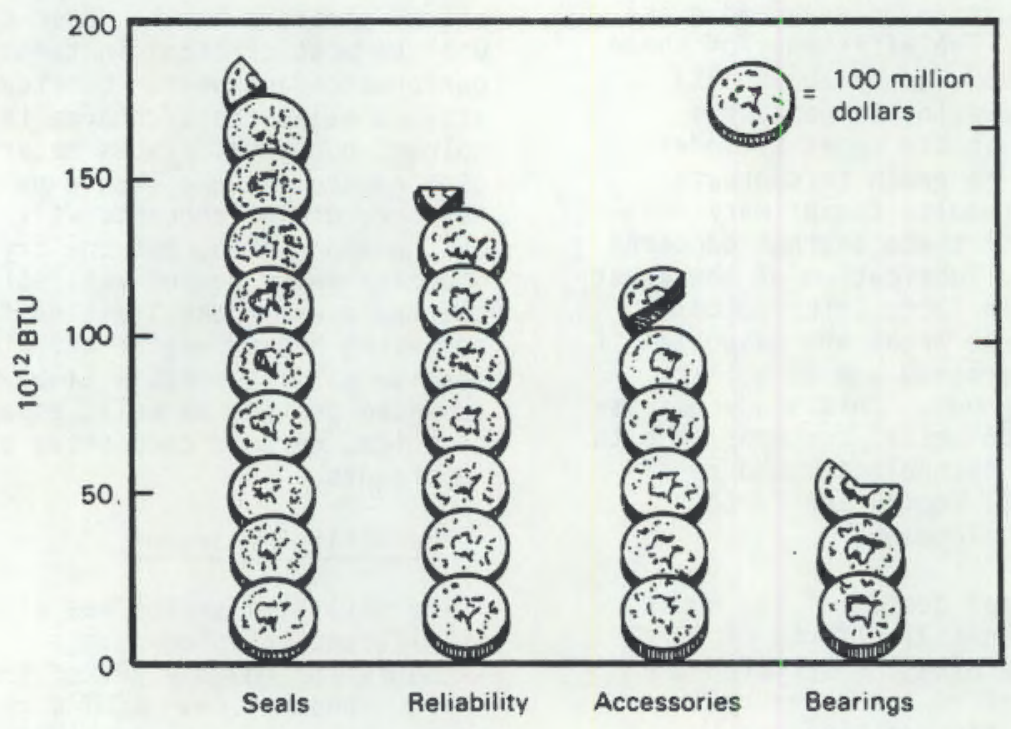

FIGURE ES.4. Potential Energy Savings for the Utilities (Based on estimates of installed capacity in 1983 and on an energy cost of $\$ 30$ per barrel.) 
total of 640 government-sponsored projects covering the fiscal years 1978-1983. These organizations were then contacted by mail, followed by visits and/or phone discussion. Of the original 640 projects, 215 were found to be current. A detailed description of each project is included in the report.

According to this study, until several years ago tribology research emphasized component development, fluid film and elastohydrodynamic lubrication, and concentrated contacts. Since then the emphasis has shifted dramatically, and research efforts now concentrate on lubricants, materials and coatings, and friction and wear mechanisms. There is still considerable interest in rolling contact bearings and seals, as well as in early failure detection in maintenance technology.

The study also concluded that most current tribology research is related to DOD objectives of longer life, low maintenance/ failure-free machinery, and the basic understanding of friction, wear, materials, and coatings. High-temperature lubrication also continues to be a major objective in tribology research; the effects of new materials and solid lubricants on current temperature limitations are also being studied. Coatings are receiving the most attention in general materials development. Figure ES.5 shows a breakdown of the materials considered in the 215 projects.

The author also concluded that current programs generally do not emphasize energy or materials conservation. Design predictability and composite materials are other areas that are receiving little attention. Finally, the study cancluded that current
U.S. Government high-temperature lubrication work is the most applicable to energy conservation goals.

INDUSTRY PERCEPTIONS OF GENERIC RESEARCH NEEUS IN TRIBOLOGY

Because transferring information to industries is a major part of the ECUT program, ECUT conducted a survey of industry perspectives on tribology $R 8 D$ needs. This survey, conducted by Sibley and Zlotnick, involved interviewing industry contacts to discover what research results are needed.

The authors held in-depth discussions with engi neers and managers from 27 companies. These companies were chosen by defining different tribological categories (such as transportation, power plants, seals, gears, aerospace, etc.). At least one company was then selected for each category, and two or three were chosen for categories that are particularly important to the ECUT program. The purpose of this study was not to produce statistically significant findings, but rather to represent many different viewpoints and a variety of interests.

The authors' main emphasis was on determining the engineering limitations imposed by tribology considerations. They also tried to determine the type and funding level of current generic tribology R\&D in each company, although only pon-proprietary information was avai lable. (a)

Based on the levels of generic tribology $R \& D$ in the 27 individual companies, the authors then estimated total tribology R\&D in each industrial segment. Although this approach is obviously limited, reasonably

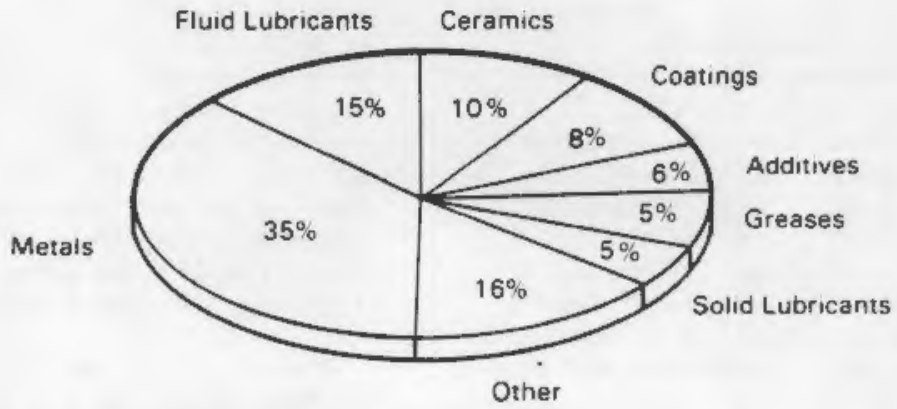

FIGURE ES.5. Materials Under Consideration in the 215 Current Government-Sponsored Trbology Projects

(a) "Generic" R\&D in this case is basic research that is not di rected toward a spectfic end use or product. 
TABLE ES.3. Estimate of Generic Tribology R\&D and Total R\&D Budget for Representative Industries (In \$M)

\begin{tabular}{|c|c|c|c|c|}
\hline Classification & Company & $\begin{array}{l}\text { Total } \\
\text { R8D(a) } \\
\end{array}$ & $\begin{array}{r}\text { Gener } \\
\text { Tribology } \\
\end{array}$ & ${ }_{S D}(\mathrm{~b})$ \\
\hline Liquid Lubricants & Mobil & 188 & 1 & . \\
\hline Transportation & Ford & 1764 & 1 & \\
\hline Aerospace & Pratt \& Whitney & 835 & 0 & \\
\hline Powerplants & Caterpillar & 234 & 0 & \\
\hline Seals & Crane & 10 & $<1$ & \\
\hline Rolling Elements & TRW & 109 & $>0$ & \\
\hline Gears & Eaton & 100 & 20 & \\
\hline Sliding Bearings & Tribon & 0 & $>0$ & \\
\hline Filters & Pall & 7 & 0 & \\
\hline Small Mechanical & Xerox & 565 & $>0$ & \\
\hline Ceramics & Norton & 26 & $<1$ & \\
\hline Coatings & Union Carbide & 240 & $<1$ & \\
\hline \multirow[t]{2}{*}{ Forming } & Bethlehem & 46 & $\leq 1$ & \\
\hline & & 4124 & 6 & \\
\hline
\end{tabular}

(a) From the report to the Securities and Exchange Commission for 1982. (Source: "Business Week," June 20, 1983.)

(b) 8ased on discussions with research staff and referring to only company-funded generic tribology R\&D.

accurate estimates were developed of the amounts of generic tribology R\&D being conducted in each of the industrial segments. The results for the individual companies are sumarized in Table ES.3.

These authors concluded that industry funds only a very limited amount of generic tribology research. Some 'hidden' generic $R \& D$ is incorporated into the companies' design manuals, but much of this information is proprietary. As illustrated in Table ES.3, some industry segments have little or no generic tribology R\&D. Tribology research efforts are often too small to be likely to improve the state-of-theart; ceramics is an example of an area in which the funding levels are too small to promote significant advances, although industry has expressed considerable interest in this area. However, the liquid lubricant research budget in the transportation indus tries is substantial.

The industry representatives expressed interest in the ECUT Tribology Program, and also in obtaining a fundamental physical understanding of tribological mechanisms. The industry contacts also requested more effective presentations of research results, especially results in a form that design and development engineers could readily use.
Another industry concern involved developing more realistic laboratory tests and more rational performance standards.

\section{CONCLUSIONS}

The six ECUT surveys summarized here were conducted to provide an overview of the major tribological sinks and the current state of U.S. tribology research. Although much of this preliminary ECUT work involved general surveys and samplings, the overall picture is consistent and reveals areas of major concern. The findings in the general surveys have been largely substantiated by the two focused studies on metalworking industries and the advanced diesel engine. These results are being used to support ECUT Tribology Program planning.

These surveys describe the current status of U.S. tribology R\&D in 1984; the findings will be updated as necessary. Much of the information is necessarily somewhat speculative and theoretical, and many of the general findings have not yet been fully corroborated. This is due in part to the lack of previous research; improving this initial information should be an important goal of current research. In particular, identifying tribological mechanisms should 
be emphasized in order to define specific research projects. Further discussion with industry representatives is also needed.

The five key results from these ECUT studies are listed below:

1. Advanced tribo-materials, coatings, and lubricants must be developed to further improve energy efficiency. Although tribological improvements can be made with the current technology, new and innovative materials and designs (such is the advanced diesel engtne) are rieeded to significantly increase energy efficiency.

2. Tribological mechanisms that shorten equipment life and cause excessive downtime and repair should be ident1fied and studied. Initial research shows that these indi rect energy losses from materlal wear are often greater than the direct energy losses from friction. In addition to the energy conservation 1 mpacts, reducing these losses could also stgnificantly improve industrial productivity.

3. Generic tribological research wll affect all three major sectors, since similar tribological mechanisms are found in many different processes. A.l though the transportation sector has the largest tribological energy loss and the greatest potential for energy savings, there is signiftcant energy savings potential in all sectors. Thus research results must be effectively transferred to all sectors.

4. Meaningful performance tests and standards must be developed so that new cesigns and products can be accurately evaluated. Laboratory tests that accurately reflect real-world condt tions are badly needed. Total system testing is vital, since tribological energy losses are often caused by complex interactions between all the components of a system.
5. Continuing communication with industry is critical to ensure that industry research needs are addressed and that the results are adequately transferred.

These results supported the development of the ECUT Tribology Program plan for 1985. The research program is divtded into two parts. The Mechanisms component includes such areas as advanced tribo-materials R\&O, Identifying and characterizing tribological mechanisms, and developing performance test requil rements. Projects in this area include developing new tribological materials, and modeling and experimental efforts to determl ne physical and chemical interactions and processes in tribological systems.

Liquid and solid lubricants, tribologica? coatings and surface modifications, and ceramic and cermet materials are specific topics to be considered. The Mechanisms area also includes efforts to develop novel characterization and testing procedures and diagnostic tools and equipment to assess the performance of tribological systems.

The second part of the research program, Design, includes such topics as design and reliability modeling of components, systems, and system assemblies. Industry is directly involyed in these projects. The Design area wil also establish a data center to gather and disseminate information on tribology. These projects concentrate on generic tribology R\&D, including energy losses from material wear.

Clearly, tribology research can have a major impact on energy use and conservation in the U.S. Much of the needed research identified in these studies is innovative and high-risk, which makes tribology a vital and appropriate area for-ECUT support. Thus the ECUT Tribology Program, wth industry particlpation and cooperation, will continue 1 ts efforts to reduce the enormous energy losses caused by friction and wear. 
The continuous evolution of higher power density propulsion systems has always fueled the search for materials and lubricants with improved thermal and/or durability characteristics. Tribology of the upper cylinder region is the major technology roadblock in the path of the adiabatic diesel engine which has an energy reduction potential that exceeds that of all other engine development types. National programs funded by the U.S. Department of Energy (DOE) and Department of Defense (DOD) have funneled sizable resources towards the development of reliable, cost affordable ceramic components while the formidable lubrication, friction and wear limitations of the diesel have been largely ignored.

Dvercoming the diesel tribology hurdles in the upper cylinder region have been exacerbated by:

1. a lack of appreciation of the interdependent, systems nature of the materials-lubricants-design interfaces in the piston-cylinder-ring belt area

2. the paucity of the lubricants technology base for ceramics

3. the absence of a meaningful lubricant market incentive for the private sector.

This tribology assessment, sponsored by the Energy Conversion and Utilization Technologies (ECUT) Program of DOE, resulted in the following major conclusions and recommendations.

CONCLIJSIONS

1. A low friction and a low wear seal between the ring belt and cylinder bore are the most critical tribology functions in the diesel combustion chamber.

2. Development of solid lubrication systens will not satisfy the simultaneous low friction and low wear requirements in the upper cylinder area. 
3. Development of separate upper cylinder liquid lubrication systems offers the most attractive design alternative for meeting the operational goals of future "minimum cooled" diesel engines.

\section{RECOMMENDATIONS}

1. Accelerated and integrated R\&D efforts for developing compatible, high temperature, lubricant basestocks and additives for ceramic and oxide coated alloy systems are required.

2. The ECUT Program should concentrate on mechanistic based research designed to extend the knowledge of lubrication and wear mechanisms and their respective modes of degradation. A combined descriptive (analytical) model-materials characterization-tribological evaluation methods approach is recommended.

Recommendations for specific R\&D tasks are proffered in the text. The tables and figures at the end of the manuscript serve as an Executive Summary outline for this assessment. 


\section{CONTENTS}

EXECUTIVE SUMMARY OF THE TRIBOLOGY SERIES

i i i

SIMMARYY

$x i$ ii

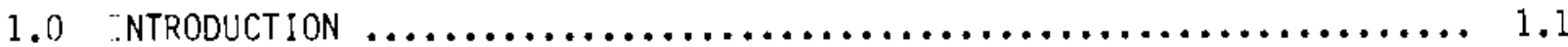

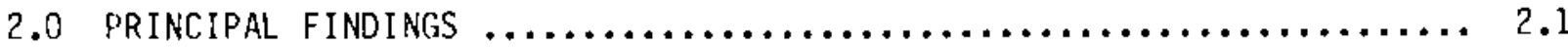

2.1 CURRENT HEAVY DUTY DIESEL TECHNOLOGY $\ldots \ldots \ldots \ldots \ldots \ldots \ldots \ldots \ldots \ldots \ldots \ldots$

2.2 MECHANICAL DESIGN-UPPER CYLINDER TRIROLOGY RFLATIONSHIPS $\ldots \ldots \ldots 2.2$

2.2.1 Piston Ring-Liner Conformity ................... 2.3

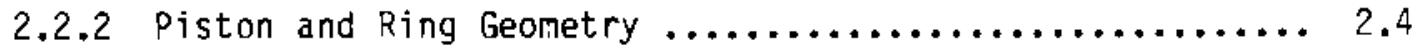

2.2 .3 Piston Ring Clearances $\ldots \ldots \ldots \ldots \ldots \ldots \ldots \ldots \ldots \ldots \ldots . . \ldots \ldots$

2.2.4 Liner Cross Hatching-Piston Land Clearances .......... 2.5

2.3 CHEMICAL-UPPER CYLINDER TRIBOLOGY RELATIONSHIPS $\ldots \ldots \ldots \ldots \ldots \ldots$.

2.3.1 Lubricant Basestocks ......................... 2.7

2.3 .2 0il Additives $\ldots \ldots \ldots \ldots \ldots \ldots \ldots \ldots \ldots \ldots \ldots \ldots \ldots \ldots \ldots . . . \ldots$

2.4 ADVANCED DIESEL DEVELOPMENT-TRIBOLOGY STATUS $\ldots \ldots \ldots \ldots \ldots \ldots \ldots . .12$

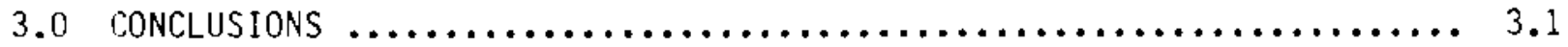

4.0 RECOMMENDATIONS $\ldots \ldots \ldots \ldots \ldots \ldots \ldots \ldots \ldots \ldots \ldots \ldots \ldots \ldots \ldots \ldots \ldots \ldots \ldots$

4.1 SINGLE LUBRICATION SYSTEM-INSULATED UPPER AND NORMAL

LOWER CHAMBERS R\&D RECOMMENDATIONS $\ldots \ldots \ldots \ldots \ldots \ldots \ldots \ldots \ldots \ldots \ldots . . \ldots .1$

4.2 SEPARATE UPPER CYLINDER-LOWER CRANKCASE LUBRICATION SYSTEMS

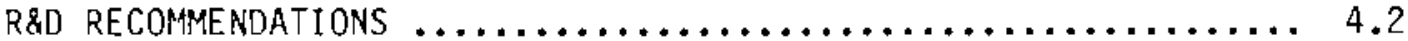

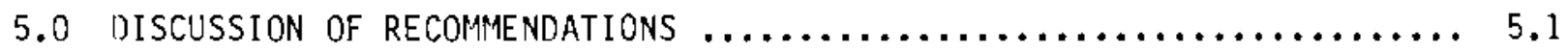

6.0 ROLE OF THE ECUT TRIBOLOGY PROGRAl $\ldots \ldots \ldots \ldots \ldots \ldots \ldots \ldots \ldots \ldots \ldots \ldots \ldots \ldots \ldots \ldots \ldots$

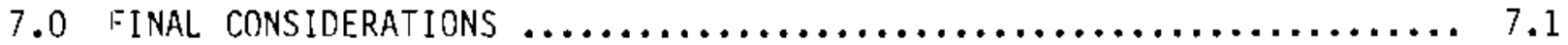

APPENDIX - ANTIWEAR-ANTIOXIDANT MECHANISMS $\ldots \ldots \ldots \ldots \ldots \ldots \ldots \ldots \ldots \ldots \ldots \ldots$

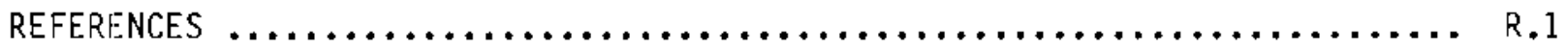




\section{$\underline{\text { FIGURES }}$}

1.1 BSFC of Engines $\ldots \ldots \ldots \ldots \ldots \ldots \ldots \ldots \ldots \ldots \ldots \ldots \ldots \ldots \ldots \ldots, 1.2$

1.2 Schematic of Turbo Compound Engine $\ldots \ldots \ldots \ldots \ldots \ldots \ldots \ldots \ldots \ldots \ldots \ldots . .3$

2.1 Schematic of Hydrodynamic Lubrication Model of Piston Ring ........ 2.5

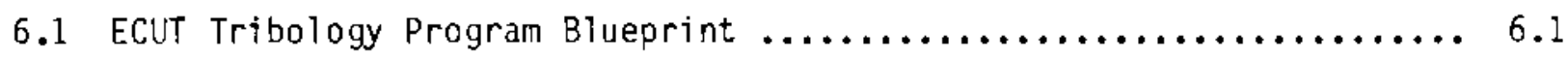

\section{TABLES}

1.1 Summary of DOE Heavy Duty Transport Technology Program $\ldots \ldots \ldots \ldots \ldots$...?

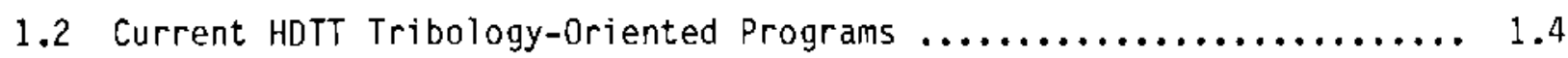

2.1 Mechanical Energy Loss Distribution in Caterpillar 3406 Engine and Its Auxiliary Equipment $\ldots \ldots \ldots \ldots \ldots \ldots \ldots \ldots \ldots \ldots \ldots \ldots \ldots \ldots \ldots \ldots \ldots \ldots, 2.1$

2.2 Mechanical Parameters Affecting Performance Durability of

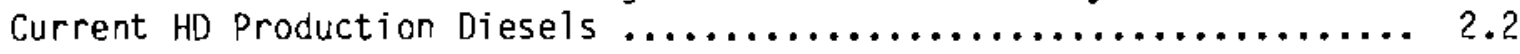

2.3 Chemical Parameters Affecting Performance/Durability of Current HD Production Diesels $\ldots \ldots \ldots \ldots \ldots \ldots \ldots \ldots \ldots \ldots \ldots \ldots \ldots, 2.3$

2.4 Previous/Current Advanced Diesel Tribology Efforts $\ldots \ldots \ldots \ldots \ldots \ldots . .2 .12$

2.5 Summary of Previous/Current Advanced Diesel

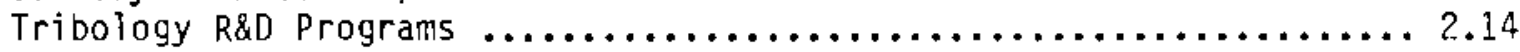

3.1 Tribology Limiting Components for Advanced Heat Engines $\ldots \ldots \ldots \ldots . . . .3$

3.2 Recommended Areas of Research Emphasis for Adiabatic Diesel Tribology Needs $\ldots \ldots \ldots \ldots \ldots \ldots \ldots \ldots \ldots \ldots \ldots \ldots \ldots \ldots \ldots \ldots \ldots \ldots . .3$ 


\subsection{INTRODUCTION}

The last decade has seen a worldwide explosion in research, development and implementation activities for improving energy conversion and conservation for a broad spectrum of societal uses. Dominant among several technology areas has been the pursuit of engine designs and associated technologies with greater thermal efficiency.

The United States Department of Energy (DOE) has underwritten major investments in technology development of the Automotive Gas Turbine and Automotive Stirling Engines for the past several years. The workhorse of transportation and the industrial marketplace, the diesel, had been neglected by government R\&D agencies until the Army initiated the development of the waterless, so called "adiabatic" diesel engine, $(1,2)$ and the Defense Advanced Research Projects Agency (DARPA) funded the Compound Cycle (Diesel) Turbine

Engine ${ }^{(3)}$ Program. However, DOE has recently started a technology base effort for advanced diesel engines. The objective, rationale, key problem areas and approaches of this initiative, called the Heavy Duty Transport Technology (HDTT) Program, are summarized in Table 1.1. The HDTT program rationale can best be appreciated when one compares the fuel efficiency (consumption) of an adiabatic diesel with other types of engines as a function of percent power. (4) The efficiency of the adiabatic diesel presented in Figure 1.1 is based cin a heat-insulated, waterless, turbo-compound design. The American Society of Mechanical Engineers (ASME) estimates that the introduction of the adiabatic engine and continuously variable transmission in road transportation systems will reduce U.S. energy consumption by $7.4 \%$. This reduction represents approximately $\$ 11$ billion per year.

Efficient methods of converting the additional heat energy of the insulated nonwater-cooled design depend not only on necessary improvements in the thermal insulation and durability of primary engine components but on advances in efficiency of critical power-recovery system components: the turbocharger, the power recovery turbine, the power transfer system, as well as the air-toair aftercooler. The diagram in Figure 1.2 illustrates the major components 
TABLE 1.1. Summary of DOE Heavy Duty Transport Technology (HDTT) Program

Objectives - Provide technology base for inclustrial development of advanced HD transport engines for long haul trucks

Rationale - Significant improvement potential in specific fuel consumption (48\% versus $35 \%$ thermal efficiency of current engines)

Key Problem - Combustion chamber insulation clurability

Areas

- Upper cylinder friction and wear

- Efficient energy conversion of hot exhaust gases

Approach - Initiated 20 some contracts for key technology developments in areas of components, waste heat, materials, tribology and systems

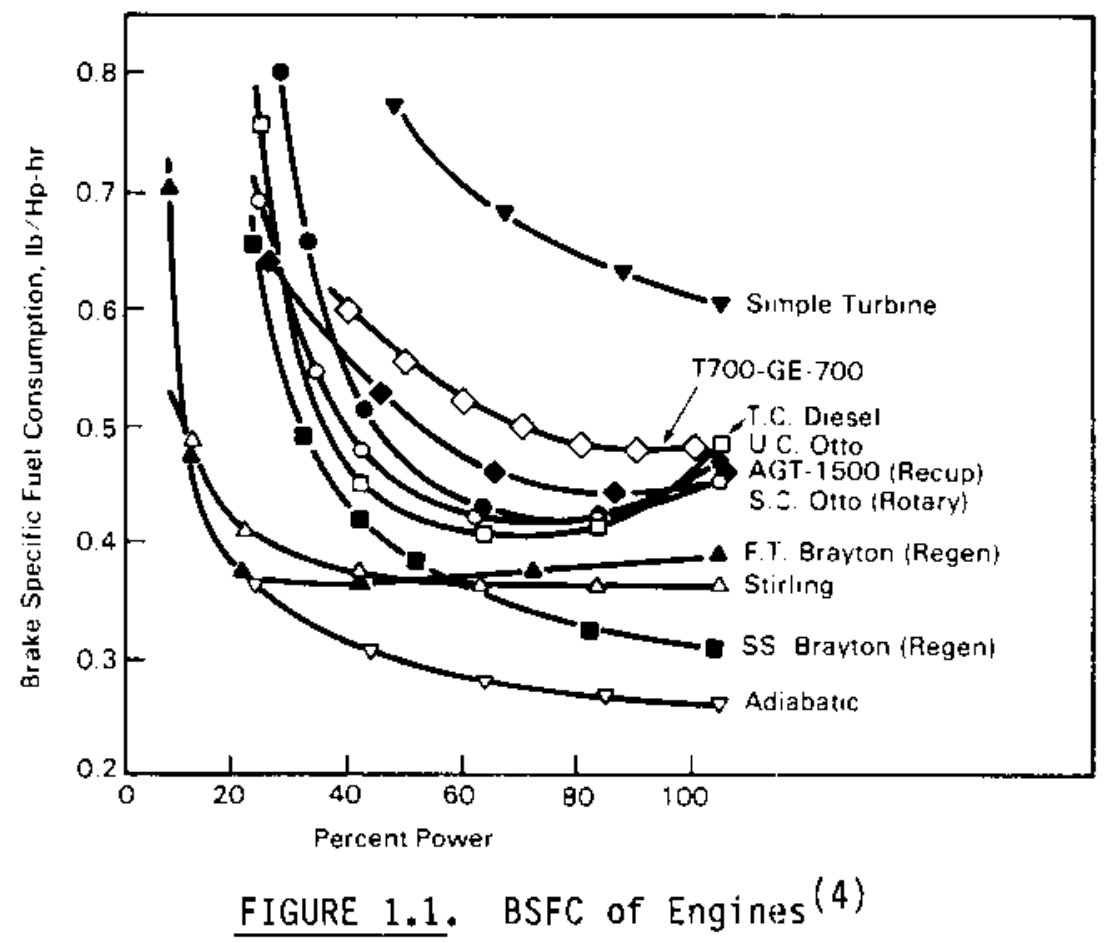

of a Turbo-Compound engine. Combined analytical and experimental engine design studies have demonstrated that efficiency in $48 \%$ range is achievable. (5)

The higher thermodynamic efficiencies demanded by these various types of heat engine design concepts will depend on the development of reliable and durable ceramic materials and coatings. Therefore, DOE is also funding a major 


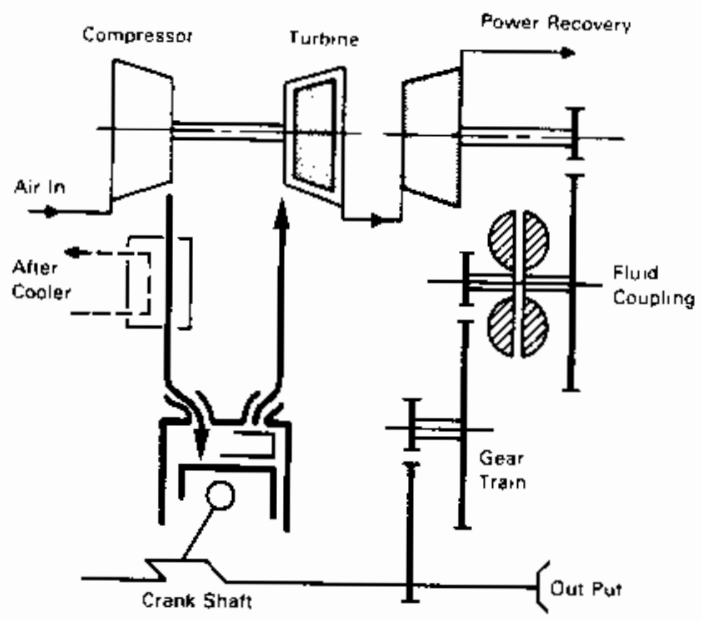

FIGURE 1.2. Schematic of Turbo Compound Engine(5)

R\&D thrust in ceramic heat engine structural materials. (6) Engine testing, however, has indicated that tribology problems, particularly in the upper cylinder region, present formidable development hurdles. (7) Naturally, concern is growing among engine developers and government officials that the full potential of ceramic componentry and therefore these advanced engines will never be realized unless associated tribology advancements are forthcoming. While the HDTT program has initiated a few small tribology-oriented programs (see Table 1.2), these resources are nowhere near the magnitude of those addressing ceramic structural durability issues.

Therefore, the ECUT Tribology Program contracted with TA\&T, Inc. to 1) conduct an assessinent on tribology state of the art and shortfalls of mechanical componentry considered most vital to achieving diesel engine performance and durability goals, and 2) proffer R\&D recommendations that, if followed, should allow ECUT to advance the tribology technology base needed by these future engines. An analysis of interactions between triboconditions (speed, load, load-frequency contact geometry, and chemical environment), bearing materials, lubricants and lubrication systems relative to their combined influence on component and engine wear and performance served as the basis for the recommendations. 
TABLE 1.2. Current HOTT Tribology-Oriented Programs

Improved high-temperature coated piston rings TRW/Ramsey Division

Gas piston ring design

"YT I

Solid lubricated (SL) design model

SKF

Ceramic (carbide) piston rings

SWRI

$S L$ coated or infiltrated metals and ceramics

'Nestinghouse R\&D 


\subsection{PRINCIPAL FINDINGS}

\subsection{CURRENT HEAVY DUTY DIESEL TECHNOLOGY}

A review of diesel R\&D literature clearly illustrates that a complex and dynamic combination of mechanical, chemical and thermal interactions between fuel, lubricant and engine components affect the performance and durability of current heavy duty supercharged diesel engines.(8) The emphasis of the advanced diesel development programs on the piston-ring-liner systems is well justified on 1) the basis of mechanical energy losses and 2) the difficulty of achieving improved or equivalent friction and wear performance at higher temperatures. Greater than 50\% of mechanical energy losses in a typical over-theroad heavy duty diesel truck engine occur within the cylinders (see Table 2.1). Other engine component areas which will require associated tribology advancements include the crankshaft-connecting rod bearings, the camcam followers and the rest of the valve train. ( 9 ) However, this assessment concentrated primarily on the cylinder-ring-piston system because of the technical complexity of its tribology shortcomings.

The optimization of upper cylinder and lubricant materials and component design has been historically dependent on a very large and impressive empirical knowledge base. As usual, these empirical developments have been followed

TABLE 2.1. Mechanical Energy Loss Distribution in Caterpillar 3406 Engine and Its Auxiliary Equipment

\begin{tabular}{|c|c|c|}
\hline \multicolumn{2}{|c|}{ Components } & Percentage Loss \\
\hline Cylinder kit & & $55 \%$ \\
\hline Crankshaft, camsh & aft, valve train, gears & $21 \%$ \\
\hline 0 il pump & & $11 \%$ \\
\hline Water pump & & $10 \%$ \\
\hline Fuel pump & & $3 \%$ \\
\hline Test Conditions: & $\begin{array}{lr}\text { Piston Speed: } 2275 / \text { min } \\
\text { Fluid Temperatures: } & 0 i 1 \\
& \text { Coo }\end{array}$ & $\begin{array}{l}\text { (mean) }-15 \mathrm{~W}-40 \text { oi? } \\
190 \pm 1.5^{\circ} \mathrm{F} \\
\text { ant } 182 \pm 1.5^{\circ} \mathrm{F}\end{array}$ \\
\hline
\end{tabular}


by numerous analytical and experimental efforts to uncover the basic mechanisms associated with these real-world engineering practices. The review of many of these studies resulted in a qualitative appreciation, at least, of the key functional roles and problems that the design of the cylinder liner and piston rings plays in not only upper cylinder friction and wear functions, but, more importantly, overall engine performance and durability.

A summary of these liner-ring design parameters and the principal degradation modes is presented in Table 2.2. Although shese mechanical design parameters are depicted as separate entities in Table 2.2, they are obviously interrelated. Piston ring-liner design has a major influence on the nature of the chemical reactions between the iubricant basestocks, additives, fuels and piston ring-iiner surfaces. The principal chemical degradation mechanisms are presented in Table 2.3 for the lubricants, fuel and ring-liner materials. These chemical degradation modes and rates are strongly influenced by the ringliner geometrical and mechanical design parameters. (10)

\subsection{MECHANICAL DESIGN-UPPER CYLINDER TRIBOLOGY REL_ATIONSHIPS}

Separating and assigning quantitative contributions of these various individual parameters to key failure modes is virtually impossible due to their

TABLE 2.2. Mechanical Parameters Affecting Performance Durability of Current HD Production Diesels

Parameter

Ring-liner conformity

Ring and piston geometry

Piston ring-land clearances

Liner cross-hatch honing patterns

Piston upper land-cylinder clearances
Functional Problem Areas

oil film thickness, friction, oil consumption control

0il film thickness, friction, oil consumption control

Deposits, ring sticking oil consumption control

Oi 1 consumption control

Piston 1 and deposits, bore polishing, oil consumption control 
TABLE 2.3. Chemical Parameters Affecting Performance/Durability of Current HD Production Diesels

\begin{tabular}{ll}
\multicolumn{1}{c}{ Parameter } & \multicolumn{1}{c}{ Functional Problem Areas } \\
$\begin{array}{ll}\text { Lubricant basestocks } \\
\text { Antiwear, antioxidant detergent-VI } \\
\text { additives }\end{array}$ & $\begin{array}{l}\text { Thermal-oxidative stability corrosive } \\
\text { wear, deposits }\end{array}$ \\
Fuel composition & $\begin{array}{l}\text { Acid formation, corrosive wear, } \\
\text { deposits }\end{array}$ \\
Ring-liner-piston materials & Wear, catalytic oil degradation
\end{tabular}

highly-interdependent nature. However, certain design factors are extremely critical and the following examples of the role of piston ring-liner geometry nelp illustrate this point.

\subsubsection{Piston Ring-Liner Conformity}

Heavy-duty diesel pistons usually contain two compression rings and an oil ring. The compression rings are fabricated in open-ended cam shapes so that they experience uniform tension around the cylinder bore circumference. In addition, a perfect $360^{\circ}$ witness lap is generally machined on the outside edge of the ring to help ensure a complete circular seal at the start of break-in. Further, pistons are usually fabricated in noncircular elliptical shapes and tapered from bottom to top to improve the circular fit to the cylinders. These odd-shaped pistons offset the effects of nonsymmetrical combustion gas pressures and thermal expansion differences that occur during engine operation. (11)

In spite of all these piston and piston ring-design precautions, manufacturing variations and nonuniform thermal gradients create ring-liner gaps in real engines. Nonuniform ring sealing and ring wear causes increased leakage of combustion gases by the rings (blow-by). $(12,13)$ Blow-by accelerates the rate of oil volatilization, oxidation and deposit formation, leading eventually to aggravated ring and liner wear and, ultimately, piston scuffing. (14) 


\subsubsection{Piston and Ring Geometry}

Piston ring shape also plays an important role since it contributes directly to the formation of an $0 i 1 \mathrm{film}$ wedge of finite and varying thickness throughout the piston stroke cycie. (15) Hydrodynanic lubrication theory predicts that the oil film thickness is directly proportional to speed and viscosity of the lubricant and inversely proportional to the load. Therefore, theory predicts that immediately after compression top dead center where the ring speed and oil viscosity are the lowest and the load is the highest, the minimum thickness should result. Direct and indirect measurements in fired engines have confirmed this result. $(16,17)$

A hydrodynamic lubrication model of a piston ring illustrates a bevelshaped ring profile and its associated pressure peak and oil wedge thickness in Figure 2.1. At top and bottom dead-center (TDC and BDC) portions of the piston stroke, the ring shape should produce a squeeze film effect which helps keep ring-liner surfaces separated. Direct and indirect measurements in fired engines have shown that oil film breakdown and boundary lubrication do occur at TDC and BDC. Thinner-than-predicted oil films have been attributed to insufficient oil supply, ring inclination and twisting and lubricant cavitation by various investigators. $(16,18)$ Nonetheless, increased friction and wear are the result.

The lubricant film formed at the piston-cylinder wall interface is equally important as the ring wall thicknesses since dynamic impact of piston against wall cannot only cause detectable noise (called piston slap) but can result in increased friction, wear and possible scuffing of the piston skirt. Recent development of analytical models of piston dynanics has proven useful in assessing the interrelated effects of piston-cylinder design parameters, lubricant characteristics, and engine operating conditions on piston-cylinder liner impacts and power losses. $(11,19)$

\subsubsection{Piston Ring Clearances}

Piston ring groove geometry (ring-land clearances) also plays a critical role in upper cylinder durability and engine life. $(15,20)$ Keystone- (tapered) 


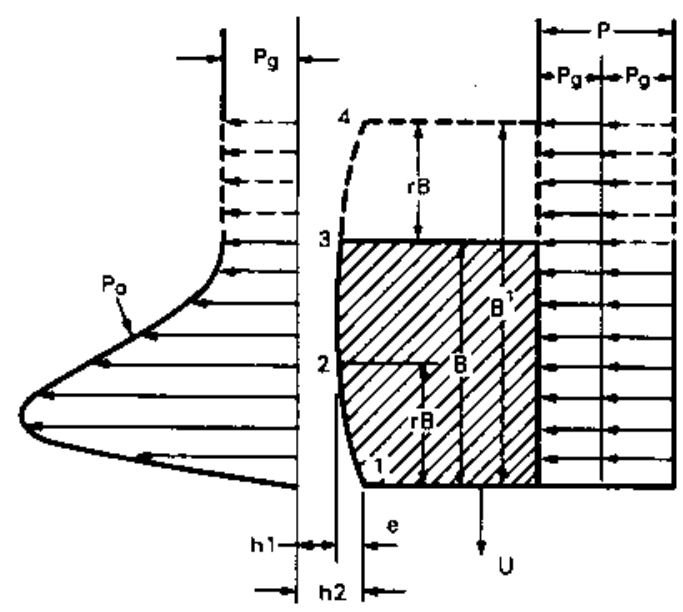

Pg: gas pressure in cylinder

Pe: elastic pressure of ring

Po: pressure in oil film

U: ring speed

hl: oil film thickness at the entrance of sliding surface

H2: minimum oil film thickness correspond to measuring one

$B^{1}$ : ring width

r: part of curved profile assumed 0.5

B: effective ring lubricating width $\mathrm{B}^{1} /(1+r)$

e: amount of worn out part assumed $\mathrm{B} 1 / 1000$

FIGURE 2.1. Schematic of Hydrodynamic Lybrj-

shaped ring grooves are used in most heavy-duty diesels to minimize buildup of carbon particles and oil degradation products that cause ring sticking.

The tapered groove permits ring movement throughout the piston cycles, significantly lessening the likelihood of ring sticking and enhanced upper cylinder wear. Experience has shown that the bottom keystone groove angle is very important in terms of ring-groove land contact loading and subsequent stickirg. Therefore, quality manufacturers exert stringent control over this groove angle tolerance (on the order of \pm 7 minutes or about one-tenth of a degree). (20)

\subsubsection{Liner Cross Hatching-Piston Land Clearances}

Liner cross-hatch honing patterns and piston upper land (above top ring) cylinder clearances are other geometrical design parameters critical to the 
maintenance of low oil consumption rates and adequate engine performance durability. (21,22) High oil consumption is usually indicative of cylinder bore polishing (removal of the cross-hatching cylinder liner honing pattern). Cylinder bore polishing, in turn, is influenced by upper piston land-cylinder clearances. Tight clearances contribute to the formation of hard, adherent upper piston land deposits responsible for the liner wear (bore polishing) phenomenon. Thus, current design practice calls for top piston lands to be cut back. With cut-back piston lands, poorly adhering, softer and less harmfui deposits are formed.(22)

In summary, the piston, piston ring and cylinder liner geometry directly affect the rate and nature of deposit formation and subsequent liner-ringpiston friction, wear and durability. The geometrical design practices cited above have been developed to minimize deposit formation and maintain control of oil consumption. In fact, diesel fleet maintenance supervisors many times use the rate of oil consumption (miles per quart of oil added) as a guide for engine overhaul since it is a good indirect measure of ring-liner wear. (23)

\subsection{CHEMICAL-UPPER CYLINDER TRIBOLOGY RELATIONSHIPS}

Problems with upper cylinder deposits, bore polishing and oil consumption appear to be on the increase in over-the-road diesels. Analysis of upper cylinder deposits indicate they result from chemical interactions between ringliner-piston materials, oil degradation products and the fuel combustion byproducts. Knowledge of lubricant formulation principals, oil degradation rates and mechanisms is required if significant advances in additive and lubricant formulation technology are forthcoming.

As might be expected, heavy duty diesel oil "CD" formulation practices focus on the optimization of the additive package for deposit control. Since the deposits are primarily the result of reactions between oxidized oil fractions, oil additives and combustion byproducts, the stability, effectiveness and compatibility of the various oil additives with engine structural materials, the seals, the fuel, the basestocks and each other are major concerns for the lubricant chemist. 


\subsubsection{Lubricant Basestocks}

\subsubsection{Refined Crude 0i1 Basestocks}

The chemistry of the lubricant basestocks also has a large influence on thermal-oxidative stability, additive receptivity and additive formulation practices and deposit formation tendencies. $(24,25)$ Most lubricant basestocks from refined crude oils consist of saturates and aromatics plus small amounts of complex nitrogen, oxygen and sulfur heterocyclic structures. Saturates consist of linear and branched $\mathrm{C}-\mathrm{H}$ (paraffinic) structures and saturated cyclic ring (naphthenic) structures. These single $\mathrm{C}-\mathrm{H}$ bond paraffinic-naphthenic structures are much less susceptible to oxidation than the aromatics, which consist of carbon atoms joined in hexagonal geometric configuration with alternating double bonds (unsaturated olefinic double bonds) between the pairs of carbion atoms. These weaker double bonds are more susceptible to oxidation. Therefore, the aromatic molecules are the principal contributors to hard deposit formation. Some of the heterocyclic compounds, sulfur and nitrogen in particular, can retard oxidation of the basestock. In general, however, they interfere with the effectiveness of the polar additives and their presence usually has to be accounted for by increasing the concentrations of the various additives.

Iceal basestocks from crude oils would contain high percentages of saturates and low percentages of aromatics and sulfur, nitrogen and oxygen heterocyclic compounds. With the general trend of greater variation in basestocks quality, crude-oil refining procedures and additive packaging tailoring are of greater concern in formulating high-quality diesel oils. Lubricant basestocks used in domestic formulations are based on solvent refining and require close attention to finished basestock chemistry and additive package formulation in order to minimize deposit formation.

Two stage hydrotreating as practiced by Gulf Canada can optimize crude quality by maximizing concentrations of saturates and minimizing concentrations of aromatics and heterocyclic compounds. (26) Dbviously, this process is more expensive than solvent refining but it does provide basestocks with higher oxidation stability and lower deposition tendencies than the currently-used solvent refined stocks. 
Diesel fuel composition can make an equally large contribution to engine deposits and wear if it contains high amounts of unsaturated olefins and dio?efins. (27) Catalytically-cracked crude stocks can contain relatively high amounts of these reactive hydrocarbons. Once again, hydrotreating can be used to saturate hydrocarbons and remove oxygen, sulfur and nitrogen compounds. The concentrations of acid neutralizing metal detergents in current H-D diesel oil formulations are targeted for a $0.5 \%$ level of sulfur impurities, a requirement which obviously would not be needed for a hydrotreated fuel.

\subsubsection{Synthetic Basestocks}

Diesel oils based totally on synthetic basestocks such as polyalphaolefins, diesters, polyol esters and polyalkylated benzene have come into the marketplace in recent years. (28) Higher initial costs, usually three to four times those of quality petroleum stocks, have limited the use of synthetic basestocks in spite of their substantially greater thermal oxidative stability. Synthetic basestocks are obviously primary candidates for heatinsulated (adiabatic) engines. The performance comparison of candidate oils based on various synthetic basestocks in high-temperature laboratory scale screening and thermal-insulated engine tests is discussed in the section on advanced diesel development.

\subsubsection{0il Additives}

\subsubsection{Detergents-Dispersants}

Standard diesel oil formulation practice calls for quantities of overbased metallic (generally calcium-based alkyl phenates and sulfonates) detergents in quantities sufficient to neutralize the acids that form during engine service. (29) In particular, they neutralize sulfuric acid which results from the water vapor (a principal combustion product) combining with sulfur oxide gases (from sulfur impurities in the fuel). (30) As seen in the accompanying structural formula,
$\left\{\left[\mathrm{CaCO}_{3}\right]_{\mathrm{m}}\right.$
$[R \prec$
$\mathrm{SO}^{-3} \mathrm{Ca}$
neutral calcium sulfonate 
several calcium carbonate (or other alkaline-Na-Mg-Ba-Carbonate) molecules are dispersed in neutral calcium sulfonate, forming suspension micelles. Unlike sulfonates, the overbased alkyl phenate structure consists of metal carbonate molecules tied to the calcium ions on the phenyl groups with the phenyl molecules being linked in chain-like fashion by sulfur atoms.

Without the overbasing, diesel engine components would experience abnormal corrosion or alternatively, the oil drain intervals would have to be shortened to uneconomical intervals. In addition to inhibiting corrosive wear, the polar nature of these organometallic detergents also promotes engine cleanliness by keeping insolubles and other deposit precursors in suspension via peptization.

Ashless dispersants, which also act by peptization, are also used in conjunction with the metallic detergents to reduce deposits in the upper ring belt area. These dispersants are particularly effective, in comparison to organometallic detergents, in solubilizing water soluble acids and preventing them from reacting with metal surfaces. These dispersants are usually nitrogen containing compounds (succinimides) that consist of a polar $N$ end that attracts the acid and a long organic tail (R) that keeps the micelle in suspension. Together, metal detergents and succinimide dispersants have rendered modern oils quite resistive to varnish and deposit formation. Their limited thermal stability presents potential problems in the high temperature environment of high-efficiency diesels. These limitations are discussed in the section on advanced diesel development.

\subsubsection{Antiwear Additives}

A wide variety of organic-based sulfur-phosphorous and chlorine additives decompose into polar components that coat the metal surfaces with films that reduce wear and inhibit catalytically-induced (secondary) oil oxidation reactions. (32) These types of additives are generally classified as antiwear additives and provide increased protection and durability for mechanical components operating in the boundary lubrication regime.

Numerous radioactive tracer and advanced-surface analytical techniques have supported the contention that these oil-soluble antiwear additives break down into highly-polar constituents which are chemisorbed on metal surfaces. 
Under the thermal-mechanical loads of an operating engine, these chemisorbed entities form inorganic films that reduce wear under conditions of boundary lubrication (metal asperity-asperity contacts).

Film-forming mechanistic studies and properties of these types of antiwear (sometimes called extreme pressure) additives have revealed their sensitivity to additive structure, presence of other oil additives and basestock chemistry, fuel chemistry, the metal alloy chemistry and detailed contact conditions of the specific moving mechanism. (32) The interrelationships of many of these parameters on antiwear additive performance are given in more depth in the appendix. A few examples relative to metal diorgano dithiophosphates are presented here for illustrative purposes.

Metal diorgano dithiophosphates are represented by the following structural formula

$$
\left[\begin{array}{c}
S \\
n \\
R \quad 0-P-S \\
. \\
0 \\
R^{\prime}
\end{array}\right]-M e
$$

where $R$ and $R^{\prime}$ are alkyl or aryl groups and Me is a metal such as zinc, molybdenum, and antimony. Zinc dialkyi dithiophosphates have been the principal antiwear additives used in gasoline and ciesel motor oils because of their excellent overall perfomance and dual antioxidant functionality. (29) Dithiophosphates are noted for their ability to prevent or destroy peroxides involved in their primary basestock oxidation process.

Several experimental studies on zinc dithiophosphates (ZDDP) and other S-P containing additives have shown that phosphorous ions play the pivotal role in forming antiwear films on ferrous alloys under loac. $(32,33)$ The sulfur and zinc ions in ZDDP are not the key film-forming ingredients, although the presence of zinc appears to broaden ZDDP's effective concentration range in 
compounded lubricants. (34) since Z0OPs are usually blended together with metal-organo detergents, succinimide dispersants and other antioxidantanticorrosion polar additives in motor oil formulations, the relative concentrations of the various additives are extremely critical in producing optimum engine performance.

\subsubsection{Additive-Additive Interactions}

Several laboratory scale studies have shown extreme concentration sensitivity between the usual overbased sulfonate, dithiophosphate, succinimide additives and the aromatics and polar impurities in the basestocks relative to antioxidant and antiwear performance. (35) The complexity of these additiveadditive interactions still leaves the formulator without fundamental understanding from which to build new chemical additives and additive packages. Antioxidants and their chemical reaction mechanisms are extremely important in formulating diesel lubricants for the adiabatic diesel. Behavior of the primary and secondary amines, which are commonly used in high-temperature synthetic jet oils, and ideas for synergistic additive-additive development, are discussed in the appendix.

\subsubsection{Substrate-Additive Interactions}

Several investigators have shown that differences in steel composition and the surrounding gaseous atmosphere $\left(\mathrm{O}_{2}, \mathrm{H}_{2} \mathrm{O}\right.$, etc.) affect the kinetics and composition of antiwear coatings formed. $(36,37)$ Awareness of these factors, even on an empirical basis, is extremely important in optimizing the friction, wear and durability of piston-ring-liner materials. The lack of appreciation for the lubricant chemistry-structural materials compatibility is evident in many of the past advanced diesel development efforts, as will be discussed in the next section.

\subsubsection{Solid Lubricant Antiwear. Additives}

Solid lubricants, such as $\mathrm{MoS}_{2}$, graphite, polytetrafluorethylene (PTFE) and potassium triborate suspended in liquid lubricant carriers, have been used in a number of industrial and automotive applications. $(38,39,40,41,42,43)$ Both $\mathrm{MoS}_{2}$ and graphite have been sold in fully formulated motor oils. Under sliding contact, $\mathrm{MoS}_{2}$ forms chemical bonds with iron-based engine components similar to the oil-soluble antiwear additives. $(38,44)$ Although $\operatorname{MoS}_{2}$ readily forms bond 
films in situ in pure mineral oils, interference with other polar additives competing for the surface can render $\mathrm{MoS}_{2}$ ineffective. Consequently, the synergistic and antagonistic effects of standard oil additives with MoS 2 in mineral oil suspensions have been the subject of extensive R\&D. $(45,46,47,48)$ Since the use of most, if not all, standard diesel oil additives should be avoided in high-temperature adiabatic formulations, solid lubricant-synthetic basestock combinations could become more attractive. Ideas on this subject will be discussed in the next section.

\subsection{ADVANCED DIESEL DEVELOPMENT-TRIBOLOGY STATUS}

The next step in the assessment process concentrated on a review and analysis of the progress and problems encountered with upper cylinder lubrication, friction and wear in several technology efforts on advanced diesels. The review included the Compound Cycle Turbine Engine (SCTE) and the Adiabatic Diesel (AA-750) programs, funded by the Defense Advanced Research Projects Agency (DARPA) and the Army Tank Automotive Researc' and Development Command (TACOM), respectively, are listed along with other pertinent tribology-related projects in Table 2.4.

\section{TABLE 2.4. Previous/Current Advanced Diesel Tribology Efforts}

DARPA/Air Force - Compound Cycle Turbine Engine: hybrid propulsion system with highly supercharged, direct injected two-stroke diesel geared to single radial flow turbine

TACOM/Cummins AA-750 - BHP (Brake Horsepower-Adiabatic diesel engine in $750 \mathrm{BHP}$ a $3200 \mathrm{rpm}, 0.28 \mathrm{lb} / \mathrm{BHP}-\mathrm{hr}$ minimum fuel consumption waterless, turbocompounded, insulated diesel

USAFLRL - high-temperature lubricants for minimum-cooled diesel engines

Komatsu and Mechanical Engineering Laboratories (Japan) - Tribology at high temperature for uncooled heat insulated engines

TACOM/Cummins - Minimum Friction (Advanced Adiabatic Engine) 0.25 lb/BHP-hr minimum fuel consumption using gas and solid lubricated pistons, bearings, etc., Only

TACOM/Cummins - Ceramic Turbocharger Program 
A summary of the general results and problems associated with the development, testing and evaluation of various ring-liner-lubricant combinations from these engine programs is presented in Table 2.5. Note that a wide variety of high-temperature alloys, ceramics and soft lubricating composites were tested against a spectrum of different synthetic lubricant formulations in these diesel development programs.

In general, high-temperature, high-strength (hard) alloys and ceramics in combination with polyol ester-based formulations yielded the least number of wear and deposition problems in CCTE and adiabatic diesel single-cylinder engine tests. Both test engines reached greater than $1000^{\circ} \mathrm{F}$ in the ring reversal region of the cylinder. As expected, standard additive packages used in current $H D$ diesel oil formulations contributed to heavy deposit formation. Energy-dispersive $x$-ray analysis revealed the presence of metals from the detergent, antiwear and antioxidant additives, with the calcium detergent concentration being the largest. (49) These formulations did, however, contain a high-temperature antiwear additive.

Polyol ester, polyalphaolefins and diester-based synthetic formulations exhibited excessive ring sticking, excessive oxidation and excessive volatilization, respectively, in a USAFLRL single cylinder setup that used standard diesel engine alloys and an externally heated liner that was controlled to $672^{\circ} \mathrm{F}$ in the ring belt region. (50) Once again, standard diesel additive packages appeared to contribute to deposition and wear problems. Ring sticking and deposition problems were probably accelerated because the USAFLRL diesel did not use keystone ring grooves.

Two or three other differences in the USAFLRL single-cylinder test arrangement could have also contributed to lubricant performance differences as compared to the CCTE and adiabatic diesel tests. First, the cast iron liners and ductile iron rings would accelerate (catalyze) the oil degradation as opposed to ceramics and carbides used in DARPA-CCTE and TACOM-Adiabatic programs. Secondly, the externally heated liner probably imposed a higher temperature over a larger area in the upper cylinder region than would occur in the normal combustion chamber, thereby causing a greater quantity of residual oil on the liner (grooves) to be at or near oil decomposition temperatures. 
TABLE 2.5. Summary of Previous/Current Advanced Diesel Tribology R\&D Programs

DARPA/AF CCTE

TACOM/Cummins

AA- 750

USAFLRL

Mini Cooled Lubes

KOMATSU/Hech.

Eng Lab Tribology

TACOM, Cummins

Minimum Friction

TACOH/Cumins

Ceramic Turbocharger
Ceramics, Superalloys, Composites

Coatings: PPE, PAOS, Esters, Silicones,

Fluorocarbons

Normal Engine Alloys: OPE, PAOS, Esters

Ceramics, Coatings: Mineral 011, Neat and Compound Polyol Esters

Ringless Pistons (Squeeze Fflm)

Solid Lubricated Ceramic Bearings
Bench Scale Screening:

Single Cylinder Engine

Tests

Single Cyltnder Englne

Tests

Single Cylinder Engine

Tests

Bench Scale Screening

Hard-Hard RL Materials with Polyol Ester-TAP:

oxidation, Wear, Deposition

Hard-Hard RL wth Polyol

Ester-TAP: Oxidation, Volatilization, Hear

DPE and Diester/PAO:

Oxidation, Volatilization Bearing Corrosion

Hard-Hard Like Pairs with

Neat Polyols: Adhesive

Hear, Selzure

Single cylinder Testing

Piston Wear and Scuffing

Turbocharger Testing
50,000 RPH, One Hour.

Excessive Retainer Wear 
Last, but not least, the upper piston land-liner clearances would be less over a larger (longitudinal) distance of piston travel due to greater thermal expansion of liner.

Close inspection of all the results from all the high-temperature engine programs revealed a general research methodology problem, i.e., little effort was made in designing these ring-liner-lubricant test and evaluation programs from a material and mechanical systems viewpoint.

For example, the original CCTE approach was based on the premise that the ring-liner material couples that yielded the best dry friction and wear results in bench scale tests would perform best when tested against the lubricant formulation that performed best (out of several lubricant candidates) when tested against a single alloy ring-liner combination. (48) As expected, the materials combinations that exhibited the lowest dry friction and wear were either alloys or coatings containing cobalt or molybdenum lubricious oxide formers $(51,52)$ and the best lubricants were polyphenyl ether or polyol ester formulations. However, in testing the best $R-L$ materials with the best lubricants, high friction and/or high wear occurred in every case, indicating adverse lubricant-materials interactions. Subsequent interactive lubricant development and bench scale testing with many of the originally rejected ringliner combinations resulted in promising ring-liner lubricant combinations.

The Komatsu-Mechanical Engineering Laboratory bench scale friction and wear testing of ceramic ring-liner combinations with polyol esters (neat and compounded) at $300^{\circ} \mathrm{C}$ also reflected the significance of lubricant additivering-liner chemical compatibility. (53) Falex tester wear and friction measurements at $300^{\circ} \mathrm{C}$ on like and unlike ceramic combinations lubricated with neat and formulated polyol esters indicated antagonistic reactions 1) between additives in formulated esters and certain like and unlike couples and 2) with certain unlike couples in neat ester basestocks. The like materials exhibited no unusual wear behavior in neat basestocks. Obviously, the chemical stability of oxides and carbides with respect to each other as well as the lubricant additives must be carefully considered from an overall reactivity viewpoint. 
The other two programs listed in Table 2.4 and 2.5, the Advanced Adiabatic (so-called minimum friction) ${ }^{(6)}$ and Ceramic Turbocharger, (52) are TACOMsupported programs aimed at eliminating the temperature and life limitations associated with liquid lubricants in the adiabatic diesel, particularly the upper cylinder and turbocharger regions.

These programs are based principally on the assumption that solid lubricated materials and composite systems can be developed that will satisfy the tribological requirements (friction, wear and life) of the various components without the presence of liquids. Solid lubricant materials are inherently low shear strength materials and as such, tend to wear rapidly unless speeds and loads are very low or a replenishment mechanism is available. In applications such as the piston-ring-liner system and high-speed rolling contract turbocharger bearings, replenishment is necessary since the wear must be kept to an absolute minimum over the desired life of these components. Therefore, continuous, in situ replenishment is a must for ring-liner materials that depend on a low shear strength solid for lubricaticn. If liquid lubrication were eliminated, the replenishment source would have to be carried in the fuel or supplied as powder or stick form from an external source. The harder wearresistant alloys that exhibited the best dry friction and wear properties in the CCTE testing contained lubricious oxide formers. Unfortunately, the friction coefficients for these materials are too high (around 0.2) for energyefficient ring-liner performance and long-life bearing operation.

New, more thermally stable solid lubricant composite materials that are combined with a replenishment source offer more promise for Stirling cycle engines than adiabatic diesels, at least in the foreseeable future. Dry lubricated piston ring materials and designs capable of providing conformable, low wear sealing at 700 to $800^{\circ} \mathrm{C}$ would offset parasitic heat losses and pumping losses associated with the present ring location near the bottom of the Stirling pistons. (a) The development of dry lubricated crankshaft bearings

(a) Communication with J. Dill, Apri1, 1984. 
would permit the use of a dry pressurized crankcase, eliminating the current piston rod sealing problem in the Stirling arrangement. The adiabatic diesel would also profit from a dry lubricated crankcase design.

The results from the various "gas supported" piston and piston ring and solid lubricated rolling element bearing R\&D programs suggest that extensive materials and design developments will be required before the nonliquid approaches will even show meaningful promise. More background on solid lubricating materials is given in the appendix. 


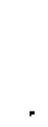

, 


\subsection{CONCLIJSIONS}

For the sake of completeness, Table 3.1 lists the most critical components and associated tribology limitations for the automotive turbine, rotary Wankel, Stirling and diesel engines. As stated in the introduction, however, this assessment dealt primarily with the low heat rejection (adiabatic) diesel technology, thanks primarily to the energy savings potential of the diesel relative to the other engine types and the newness of the HDTT program. Therefore, the genera? conclusions listed below pertain mostly to the HDTT tribology. Note, however, the need for high-temperature, dry-lubricated, low-wear material systems in the other three engines. Solid lubricated materials development is not considered a critical tribology limitation for the low heat rejection diesel, as reflected by the first conclusion:

1. An advanced low-heat rejection diesel with $48 \%$ thermal efficiency capability can probably be achieved by a careful and well-integrated piston-ring-liner synlube materials development and component design program. (To date, such a program does not exist.)

2. Development of long-1ife, low-heat rejection diesel with upper cylinder temperatures in the 1000 to $1200^{\circ} \mathrm{F}$ regime will require the use and/or development of more exotic, thermally-stable liquid lubricants and a separate lubrication system.

TABLE 3.1. Tribology Limiting Components for Advanced Heat Engines

\begin{tabular}{|c|c|}
\hline Engline & Critlcol Regenerator Seals \\
\hline Automotlve Turblne & Rotary regenerator seals \\
\hline Rotary Wankel & Apex seals \\
\hline Stirling & $\begin{array}{l}\text { Plston-cyllnder seals, } \\
\text { dry lubricated crankshaft bearlings }\end{array}$ \\
\hline Diesel & Cylinder kIt \\
\hline
\end{tabular}

\begin{tabular}{l} 
Trlbology Limitation \\
\hline Hlgh-temperature, low ear, \\
solid lubricated materlals \\
Low war, solld lubricated \\
materials \\
HIgh-temperature, low mear. \\
solid lubrlcated materlais \\
High-temperature liquid lubricants
\end{tabular}


3. Dry crankcase development, which offers major design advantages for both kinematic Stirling and adiabatic diesel engines, is dependent on significant advances in dry-lubricated rolling element bearing technology.

4. Low-wear, low-friction dry-lubricated upper cyllinder sliding components do not appear feasible without supplementary lubricant supply sources.

These general conclusions encompass a major technology development implication: namely, that the classical engine design approach--where structural materials and components-liners-rings-bearings, etc. are designed and developed by the engine or auto manufacturer independent of the lubricant--may have to be abandoned. A universal lubricant capable of adequately lubricating both hot ceramic and normal lower crankcase alloys, although simple from the engine designer's perspective, places extremely challenging, if not insurmountable, demands on the lubricant chemist.

Achieving realistic performance and durability objectives for the advanced low heat rejection diesels will, most likely, require deviations from the current design approach. Therefore, the tribology development hurdles (needs) and areas for R\&D emphasis are addressed in terms of engine design flexibility. The tribology R\&D needs for advanced diesel development are represented in a framework of separate tribological system design approaches (see Table 3.2). Obviously, there is ongoing R\&D in some of these areas but the proposed framework helps emphasize the need for an integrated approach.

A systems framework not only helps promote design, materials and lubrication systems tradeoffs necessary for more rapid development but it also enables engine designers and tribomaterials experts to more readily take advantage of evolutionary advances in lubricant and tribomaterizls development and in tribocomponent designs. Although two tribological system design alternatives represent increasing design complexity, this approach is often used to compensate for tribomaterials limitations when higner engine performance demands exceed the capabilities of current tribomaterials technology. Separate lubrication systems for the upper and lower engine chambers will probably be a must if thermal efficiencies of $50 \%$ and higher are ever to be reached. 
The areas of R\&D emphasis outlined in Table 3.1 are presented in expanded format below:

\section{TABLE 3.2. Recommended Areas of Research Emphasis for Adiabatic Diesel Tribology Needs} Tribological System Alternatives
S1ngle Lube Systen Insulated Ipper
Normal tower

Single Lube System

Tatal integrated Design

Separate Lube Systems

Insulated Upper-Homal Lower
Major Development Hurdles Syn lube and addtives with sufficient antioxidant, ant iwear and antidepasition characteristits for entire engine

Sym lube-additives for upper tylinder tribology: bearing-cam-seal materials for lower crankcase; solld lubricated companents only

Syn lube-additives for upper cylinder tribology: self replenishing soldd lubrication systems
Areas of Research Emphasis

New and improved lob scale axidation and deposition tests

Ceranics wear-deposition tendencies with conventional additives and syn lubes Lube-addftive combinations for minimal deposition and wear

Solid lubricant suspensions-antiffiction. ant wear and antideposition contributions high-temperature antloxidant mechanism and develapment studies

IC Moterfais selection-lubricant compatio bility testing

Solld iubricated rolling element bearing performance modeling

Low wear, solid lubricated retalners

Same as liquid lubes above

Dynamic modeiting of silding dry contacts solld lubricated ceramic composites Self replenishing solid lube cancepts Lubricant transfer and adheston studies Development of lab scale component sinulation tests 


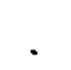




\subsection{RECOMHENDATIONS}

The following R\&D areas are recommended for further development, based on the results of this study.

4.1 SINGLE LUBRICATION SYSTEM-INSULATED UPPER AND NORMAL LOWER CHAMBERS (CURRENT, CONVENTIONAL DESIGN APPROACH) R\&D RECOMMENDATIONS

1. New and/or improved laboratory scale tests capable of differentiating between high-temperature thermal-oxidative stability and deposition characteristics of individual basestocks, additives and compound lubricants relative to the engine environment. Implicit in this R\&D recommendation is the need to develop an oxidized fuel catalyst that simulates chemical influence of the combustion byproducts.

2. Baseline characterization of thermal-oxidative-deposition behavior and upper temperature limits of available high-temperature diesel oil additives; antioxidants, detergents, dispersants, antiwear additives.

3. Additive reaction mechanistic studies, (i.e., amine alkali salt syergistic antioxidant mechanisms) for new insight into development of new additives.

4. Design and construction of improved laboratory-scale component simulation testers (ring-liner, cam-cam followers, rolling element bearings, etc.).

5. Friction, wear and chemical degradation characteristics (oxidation, polymerization, deposition) of various neat polyol ester and polyalpha olefin basestocks with selected ceramic couples (coated or monolithic) under simulated ring-liner contact conditions.

6. Friction, wear and chemical degradation characteristics (oxidation, polymerization, deposition) of basestock-additive combinations with selected ceramic couples under simulated ring-liner contact conditions. 
7. Tribo performance (adhesion, friction and wear) of solid lubricants as antiwear-antifriction substitutes for liquid additives in formulated lubricants.

8. Tailored ring-liner-lubricant materials tribo-compatibility development, i.e., multiphase surfaces and subsurfaces produced by monolithic composites or coating techniques such as cosputtering, mixedchemical vapor deposition, secondary ion implantation, etc., which promote favorable antiwear and antifriction film formation via interaction with lubricant additives (see also hybrid lubrication systems in the Design II alternative).

9. Chemical and tribocompatibility studies (corrosive wear, adhesive wear) of high-temperature formulated lubricants with materials (bearing alloys, seals) normally used in lower crankcase region.

10. Selection and screening evaluation for more wear-resistant, chemically compatible materials as potential lower crankcase components with lubricants with improved upper cylinder lubrication capabilities.

\subsection{SEPARATE UPPER CYLINDER-LOWER CRANKCASE LUBRICATION SYSTEMS R\&D} RECOMMENDATIONS

1. Thermo-oxidative-deposition-iubrication itmits of more thermally stable lubricants such as polyphenyl ethers and phosphate esters as candidates for separate upper cylinder lubrication.

2. Additive compatibility and development studies if necessary.

3. Improved boundary lubrication, mixed lubrication and dry contact analytical models for reciprocating sliding: use asperity temperature analysis and incorporate kinetics of boundary film formation and removal (applies to first system as well).

4. Friction, wear and transfer-adhesion properties of new solid lubricant-ceramic composites under sliding conditions indicative of the ring-liner environment. 
5. Evaluate replenishing boundary lubrication (hybrid) concepts for wet or dry lubricated ring-liner couples, i.e., condensate films from oil additives (wet) or vaporized liquid additives systems (wet or dry) and/or solid powder feed devices (dry).

6. Improved rolling element bearing retainer models such as SEPDYN, i.e., incorporating radial-axial loads and improved, traction modules for dry lubrication schemes.

7. New, wide-temperature range, wear-resistant, solid lubricant composites for rolling element bearing retainers.

8. Analytical modeling of ring-liner dynamics as a function of design geometry, materials properties and lubricant regime (EHD-mixedboundary or gas). 


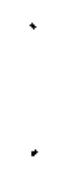




\subsection{DISCUSSION OF RECOMMENDATIONS}

The technical background underlying these recommendations is provided throughout the text as well as in the appendix of the report. It is instructive, however, to reemphasize the general rationale behind these recommendations and suggested R\&D framework.

Maintaining a tight seal between the ring pack and liner at a reasonably low friction coefficient (0.06 or less) is of utmost importance in achieving the design performance efficiency for a reasonable duration. Ring-linerlubricant combinations and lubrication systems that cannot provide both low wear and low friction over an economically viable period of engine operation will never be implemented.

These low wear/low friction, long duration sealing requirements strongly favor the development of special high-temperature liquid lubricants and lubrication systems, an area of R\&D activity which has been virtually ignored by the government and the industrial sector. The indifference of industrial R\&D laboratories can be attributed primarily to lack of market incentive.

For the turbocompounded low heat rejection diesel design capable of $48 \%$ thermal efficiency, a single lubricant and lubrication system for the entire engine nay be acceptable if sufficient lubricant R\&D is undertaken. Higher efficiency, low heat rejection diesels, where upper cylinder steady-state temperatures may reach $1000^{\circ} \mathrm{F}$ and higher, strongly suggest the development of a separate upper cylinder lubricant and lubrication system. Even in this case, the use of liquids as a mist or boundary film adsorbate is almost a must if low wear or low friction is to be maintained.

If a totally dry lubrication system were to ever become a reality, solid film replenishment sources would be required to maintain tight ring belt-liner sealing (assuming the friction losses could be tolerated). The most attractive liquidless possibility is a solid lubricated-gas film supported ring-liner combination where the gas film provides low friction and the solid lubricant minimizes friction and wear during ring lift-off as well as protects against incidental contact during high-speed engine operation. 
For a single lubrication system, the upper temperature capabilities of fully esterified high viscosity basestocks warrant serious investigation. The small quantity of lubricant and brief upper cylinder residence time coupled with good ring sealing suggest that polyol esters could possibly be in engines where upper cylinder temperatures are approaching $1000^{\circ} \mathrm{F}$.

The capabilities and deficiencies of high-temperature antioxidants (amines) and antiwear additives (phosphate esters) for both the upper and lower crankcase should be defined. In particular, the likelihood that these additives will contribute to heavy deposits at high upper ring belt temperatures is a major concern. The most stringent lubricant additive challenge, however, may be how to counteract the acid formation from sulfur impurities in the fuel without the metalijc detergents causing excessive deposit formation. In fact, the relative tendencies for these compounds to form hard, adherent deposits on plausible ceramic ring-liner materials should be datermined.

In turn, the compatibility of the favorable high-temperature basestocks and additive formulations with lower crankcase alloys such as aluminum-bronze, tin-bronze bearings and butyl rubber seals must be evaluated in terms of friction, wear, corrosion and deposition. If lubricant formulation changes required to improve tribocompatibility with normal metal alloys seriously compromise the upper cylinder tribology situation, the best upper cylinder formulations should be tested with more wear- and corrosion-resistant crankcase materials. A total materials design approach would also permit the overall performance capabilities of the lubricant formulation to be further enhanced, since the inherent wear resistance and chemical stability of ceramics decrease the likelihood that conventional formulation practices (with all the additives) have to be used.

Another area of research that deserves more in-depth attention is an assessment of the potential of solid lubricant suspensions as high-temperature antifriction and antiwear substitutes for more conventional oil soluble compounds, additives which contribute to corrosion and deposition problems. 
Some Taboratory and over-the-road engine empirical data suggest that solid lubricants may also enhance the cleanliness of the upper ring belt area. (a) Since many other internal engine components (such as the cam-cam follower, cam journal, rocker arm/fulcrum) besides the liner-cylinder tribo interface exhibit boundary friction losses, the solid lubricant additives could also contribute to reasonable gains ( 5 to $6 \%$ ) in mechanical energy recovery.

The chemical compatibility of selected solid lubricants with other lubricant additives, upper cylinder ceramics and lower crankcase alloys should be considered prior to tribobehavior evaluation in laboratory experimental test apparati. Whether or not adherence of the solid Tubricant particles to tribointerfaces is a necessary prerequisite for good antifriction and antiwear performance is another technical issue that needs to be resolved.

The second major area for R\&D emphasis is development of separate upper cylinder lubricants and lubrication systems. This activity should focus on the development of high-temperature liquid lubricants supplemented by an upper cylinder boundary lubricant additive. Preferably, an oil soluble boundary (antiwear-antifriction) additive could be found or developed that would work equally well with different types of ceramic materials (oxides, carbides, nitrides, etc.) that might be used in advanced diesel designs.

More likely, however, a lubrication approach called hybrid Tubrication in which a lubricant phase or a lubricant forming phase is incorporated in either and/or both the ring and liner materials will be necessary. This approach calls for a tailored ring-liner-lubricant lubrication system development program in which the lubricating boundary film reactant is supplied as a liquid soluble additive in the oil or fuel or as a solid additive in the oil. The design and development of a mist lubrication-system appears to warrant some serious consideration.

As mentioned earlier, this hybrid lubrication approach could also be used in a single lubrication system if compatibility of the lubricant and its degradation products with lower crankcase components could be achieved. The

(a) Communication with M. Lohrberg, March, 1984. 
resupply of a boundary film former from a recirculating liquid lubricant should be more economical than the fuel delivered additive.

However, supply of a boundary film from the fuel combustion byproducts may be a necessity if a totally dry upper cylinder design is ever achieved. 


\subsection{ROLE OF THE ECUT TRIBOLOGY PROGRAM}

The majority of the general recommendations for advanced diesel tribology R\&D outlined in Section 5.0 logically belong under the Heavy Duty Transport Technology program umbrella. What areas of R\&D responsibility and what types of research projects are relevant candidates for funding consideration under the ECUT Tribology program are the next obvious questions.

To help clarify this question, the ECUT Tribology Program blueprint shown in Figure 6.1 is useful.

Although this blueprint outlines a generic approach for development of new tribomaterials and lubrication systems, which can be transformed into more energy-efficient tribosystems (turbocharger bearing-rotor assembly) and systems (diesel engine) it must be emphasized that the ECUT policy stresses mechanistic-based approaches for advancing technologies in the field of tribology.

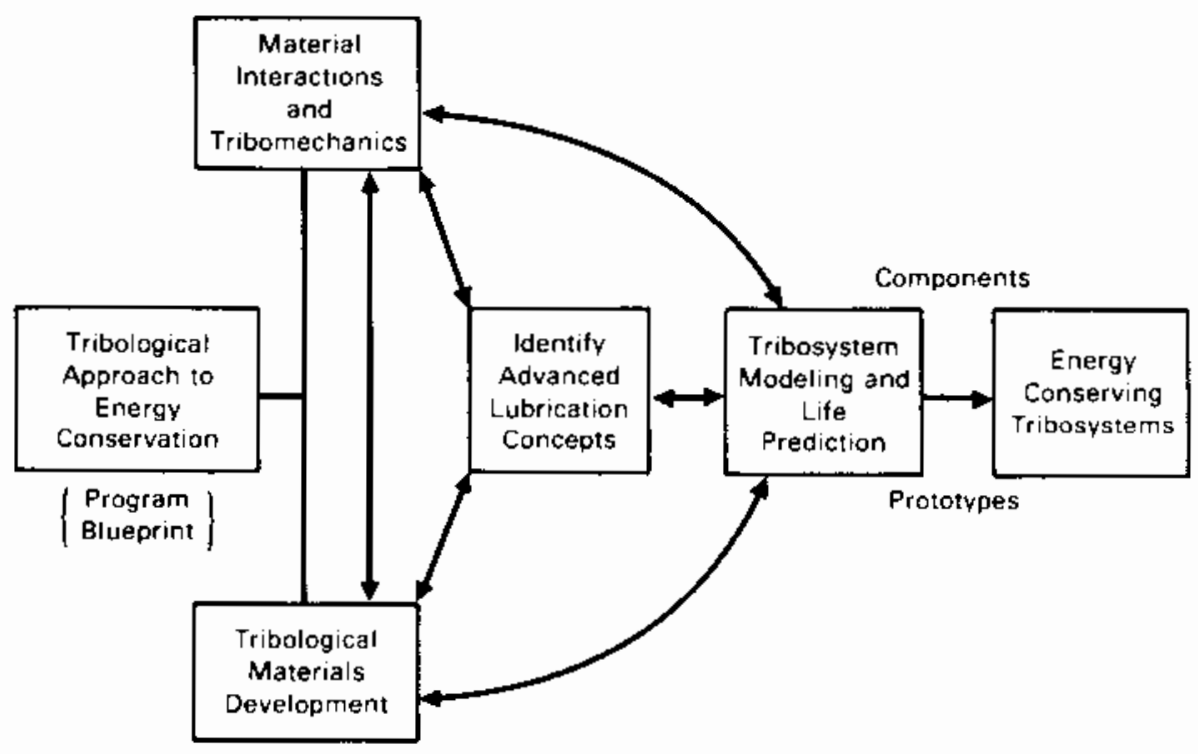

FIGURE 6.1. ECUT Tribology Program BTueprint

6.1 
Therefore, ECUT projects should be directed toward furthering understanding of the tribochemistry and tribomechanics of tribomaterials as they function in their tribosystem environment (speed, load, temperature, atmosphere) in contrast to the more empirically-based hardware demonstration projects of HDTT and Ceramic Heat Engine Technology Programs. The foundation of this approach depends on knowing materials properties - chemical structure - microstructural relationships and having hypotheses on how the property structure interrelationships (mechanisms) control the friction and wear response under varying operational environments (triboconditions). Of equal importance is knowledge of how changing triboconditions influence or mitigate the tribomaterials structure - property relationships. A properly designed mechanistic investigation consists of several important elements:

- definitive descriptions of the range of thermal, mechanical and chemical triboconditions that the tribonaterials are expected to encounter; such conditions start with prediction of speeds, loads and temperatures from tribosystem performance (i.e., bearing dynamics models)

- precision, experimental test apparati that accurately reproduce the triboconditions of interest and monitor tribobehavior and, if possible, chemical, microstructural and typographical changes in situ

- analysis of tribobehavior data (friction, coefficients, wear rates, etc.) for input into tribomaterials and tribosystem performance models

- post morten analyses of tribomaterials' chenical and microstructural properties and triboresponse data for comparison with and/or refinenent of proposed tribochemical-mechanical mechanisms

- component (tribosystem) test and evaluation to verify projected tribobehavior performance and associated degradation (faliure) mechanisms. 
This generic mechanistic scheme for heat engine tribology studies can best be illustrated by describing examples of the type of projects that deserve ECUT consideration.

The size and complexity of the matrix of interdependent and competitive and mechanical interactions that occur between lubricant basestocks, lubricant additives and ring-liner materials in a high-temperature diesel combustion environment dictate that:

1. the principal interactions be studied in a comprehensive, stepwise fashion

2. the principal interactions be compared to some known or preconceived chemical reaction sequences or mechanisms.

While the predominant chemical and mechanical degradation mechanisms for conventional diesel engine components and lubricants are fairly well understood, the chemical degradation rates and mechanisms may differ considerably for synthetic basestocks and high-temperature additives in contact with ceramic materials in the higher combustion temperature environment of a LHR diesel. To unravel the nature and kinetics of the dominant chemical degradation mechanisms, this interaction matrix of lubricant basestocks-additives-ring-1iner combinations and combustion environment shouid be subdivided into smaller groups. These subdivided tribomaterials groups, and their predominant tribological degradation mechanisms, are as follows:

a. Iubricant basestock - combustion environment interactions to understand and minimize basestock oxidation, acid formation and polymerization reactions

b. lupricant - lubricant additive - combustion byproducts interactions to minimize lubricant oxidation, acid formation and polymerization reactions that induce ring-belt corrosion and deposition phenomena

c. ring - liner - lubricant basestock interactions to understand and minimize lubricant tribocatalyses, and ring-liner chemical and mechanical wear mechanisms 
d. ring - liner - lubricant additive interactions to understand and optimize formation of antiwear, antifriction and/or anticorrosion films.

Many individual chemical processes are involved in each of these interdependent tribomaterials sets. Therefore, chemical compatibility criteria (heats of formation, solid solubility, etc.) and hypothesized reaction processes should be used in selecting lubricant basestocks, additives and ring-liner materials for mechanistic studies. Mechanistic research projects could include the following:

1. Lubricant Basestock - Lubricant Additive Combustion - Enviroment Reaction Mechanisms

Investigation of thermal-oxidative and polymerization reactions of polyalphaolefins, polyol esters and polyphenylethers with and without wear particle catalysts (mixed metals and mixed ceramics), with and without oxidized diesel fuel catalysts, or with and without additives in an oxygenated and nitrogen environments. Coupling heat change (calorimetry) and weight change measurements with detailed analyses of changing molecular structures and chemical and physical properties on a sequential materials test matrix is recommended. Favorable reactants (iron molybdenum) for inorganic phosphate antiwear or antifriction film formation could be incorporated into ringliner matrices. Monolithic composites, ion-inplanted substrates and cosputtered films or coatings are examples of techniques that could be used to incorporate film-forming dopants in ring-liner surfaces. Other antiwear film replenishment mechanisms that should be investigated include solid lubricant-liquid lubricant suspensions and/or gaseous phase reactions. Examples that could be considered include graphite fluoride $\left(\mathrm{CF}_{x}\right)$ solid lubricant interacting with a ring and/or liner material containing a fluoride eutectic solid lubricant or thermally decomposed phosphate esters reacting with a $\mathrm{Fe}$ phase(s) in a ring-liner system. Film formation and rates, chemistry, adherence, friction and wear are inportant quantitative information that should be obtained. 
2. Lubricant Additives Reaction Mechanisms

Chemical interactions between additives-lubricant basestocks, additive-additive, additive-combustion byproducts and additive-ringliner materials collectively account for reaction products that critically govern friction and wear of the upper cylinder components. The approach here calls for testing proposed chenical reaction hypotheses for various types of lubricant additives. Examples include investigation of the synergistic aromatic amine-alkali compound antioxidant mechanisms and antiwear or antifriction film formation chemistry and kinetics. Various antioxidant model compounds should be synthesized and quantitatively evaluated in laboratory-scale oxidation rate tests to test and refine synergistic oxidation inhibition mechanisms.

Selected high-temperature antiwear compounds such as oil soluble phosphate esters should be tested with ring-liner combinations that favor the promotion of adherent inorganic antiwear films.

3. Lubricant Basestock, Lubricant Additive-Ring-Liner Interaction Mechanisms

Investigate mechanisms of chemical and mechanical friction and wear between ring-liner and lubricant materials under simulated ringliner operational conditions with reciprocating ring-liner tests that simulate actual contact conditions and temperatures and monitor lubricant film thickness, ring-liner friction coefficients, and wear, with and without combustion gases. The test apparatus should also be capable of varying lubricant feed rates and delivery systems as recommended. Extensive post mortem analyses of lubricant chemistry changes and ring-liner chemical, physical (wear surface morphology) microstructural changes will be required to elucidate rate controlling mechanisms. 


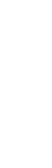

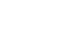




\subsection{FINAL CONSIDERATIONS}

The design, construction and refinement of improved test equipment for polymerization-film formation behavior is essential for understanding lubricant thermal-oxidative-deposition mechanisms independently and in contact with ceramic materials under simulated ring-liner reciprocating contact conditions. Examples of the test equipment and techniques that need to be developed include:

a. tandem thermogravimetric analysis-mass spectrometer apparatus using soft ionization, which would enable the thermal-oxidative stability characteristics of high-temperature organo-metallic lubricant additives to be defined

b. a reciprocating friction and wear test rig that accurately simulates ring-liner interface contact conditions and would permit hot combustion gases and lubricant feed rates to be varied.

The type of knowledge-based diesel tribology program outlined above could be accomplished more effectively via establishing cooperative, integrated projects between DOE sister programs and laboratories and prospective industrial contractors.

For example, the effects of deleterious combustion gas phase impurity reactions on various insulating ceramics and lubricants could be studied in DOE's Combustion Research Facilities at Sandia National Laboratories at Livermore, California. Various ceramic materials can be exposed to controllable combustion environments where time, temperature, chemistry and particulate content can be varied. Diagnostic techniques such as Raman spectrometry which is used to monitor yas phase chemical reactions in situ should help provide information on lubrication and ceramic structural degradation mechanisms.

Another example of a potentially attractive cooperative effort would be in the area of surface tailoring and modification of ring-liner materials to enhance their tribological performance. Ion implantation facilities at Argonne National Laboratory could be used to evaluate a number of approaches such as 
(1) implanting ions in metal substrates to enhance adhesion and decrease thermal expansion mismatch to minimize the delamination tendencies of ceramic coatings during service, 2) implanting species in ceranic or high-temperature alloy substrates or coatings to modify friction and wear behavior directly or to promote reactions with oil additives that form in-situ antiwear coatings. Extensive testing and evaluation of these ion-modified materials and coatings in simulated and fired engine environments could be cooperatively conducted with qualified industrial and governmental partners. 
APPENDIX

ANTIWEAR-ANTIOXIDANT MECHANISMS 
APPENDIX

ANTIWEAR-ANTIOXIDANT MECHANISMS

Several experimental studies of antiwear additives containing sulfur and phosphorous atoms and in particular, metal diorgano dithiophosphates, indicate that phosphorous ions play the pivotal role in forming antiwear films on ferrous alloys under load. Sakamoto, et al., chemically examined films formed with Anglamol 99, a S-P extreme pressure (EP) additive containing a high concentration of sulfur, using a carbon steel (1.1\%C) pin on a 52100 steel disk. They incrementally increased loads up to 5000 neutrons $(n) .(57) x-r a y$, Auger and ion microanalyzer's were used to show that the dark areas that spread over the whole surface were rich in phosphorous and increased relative to sulfur with increasing load. Areas where pits occurred were rich in sulfur. This finding was consistent with ZDOP wear results obtained by Forbes who used electronmicroprobe analysis to discover that sulfur existed in roughened regions while both sulfur and phosphorous were present in others. (58)

Ir a rather novel experiment, Dorinson prepared and tested a zinc-di-nbutyldithiophosphate to determine whether or not the thiono-sulfur or zinc thiolosalt (sulfur) structures played any significant role in the antiwear behavior of ZDDP. (59) The $0.75 \%$ sulfur-free zinc salt of the di-n-butyl phosphate was tested against its di-n-butyldithiophosphate equivalent in a $1: 1$ decalin-white oil mixture on a pin-on-disk apparatus using hardened cast iron alloy (cam lifter alloys) up to loads of $120 \mathrm{ksi}$ (kip per square inch) at room temperature. Wear scars and rates as a function of load exhibited such little difference between the two additives that the pentavalent phosphoric acid portion of the ester appears to be the critical antiwear constituent of the structure.

Dther studies which also support the key role of the phosphoric acid, i.e., phosphorous, include that of Barcroft and 0aniels, who found that antiscuff protection of cams tappets did not suffer when triphenyl phosphate (no sulfur) was substituted for ZDDP in an automotive engine oil.(60) 
Loeser, et al. studied EP film formation on cams and tappets in engine tests using radioactive tagged sulfur and also concluded that phosphorous was more prevalent than sulfur. $(61,62)$ More recently, Rounds, in efforts to determine the extent and mechanisms of interaction between amines and several types of ZDDPS, examined wear performance of an acid phosphate, a zinc naphthenate and dibenzl disulfide (DBDS) versus ZDDP to test the effects of sulfur, phosphorous and zinc individually. (34) He found that phosphorous was much more effective than either sulfur or zinc. Then he blended the compounds together to simulate the $Z n: P: S$ ratios of ZDDP and duplicated the performance of ZDDP. In fact, a mixture of acid phosphate and zinc naphthenate duplicated ZDDP performance, acid phosphate-DBDS exhibited that of the acid phosphate alone, and the $\mathrm{ZnN}$ :DBDS mixture was ineffective. Rounds felt that the role of $\mathrm{Zn}$ may be to broaden the concentration range over which the acid phosphate is effective.

The fact that 4-ball wear tests with acid pho'sphate-amine blends behaved similarly to ZDDP-amine blends also suggested to Rounds that an acid phosphate decomposition product could be the active ingredient in ZDDP. He postulated that ZDDP-amine interaction enhanced acid phosphate formation. ZDDP effectiveness alone also appears related to acid phosphate formation since the first step in ZDDP decomposition is the splitting off of alkyl groups as either olefin or mercaptan leaving an acid phosphate structure behind. The relative ranking in antiwear effectiveness of ZDDP appears related to ease of removal of the dihydro groups; i.e., the short chain secondary alkyl (4-methyl-2-pentyl), the short-chain primary alky? (3-methyl, 1-butyl), the long-chain primary alkyl (isodecyl) and aryl (heptyl phenyl). The sensitiv'ty of these ZDDPs to amines followed the same pattern above the critical amine concentration. Below the critical concentration, all four ZDDPs exhibited a synergistic antiwear effect with amines.

Steric factors appear to play a large role in the extent of ZDDP-amine interactions since primary $n-a l k y l$ amines give the largest interaction, with secondary and tertiary amines exhibiting correspondingly lower interaction. Anines also appeared to increase the load capacity of the ZODPs. 
Although the ZDOPs may depend primarily on acid phosphate structure for antiwear performance, they are widely known to provide a direct antioxidant function by decomposing or tying up peroxides. willermet, et al., conducted a series of systematic studies to determine the structural mechanisms involved in the antioxidant behavior of ZDDP alone and in the presence of other antioxidants in laboratory model systems and aged fully compounded lubricants from fleet tests. $(63,64)$

Their initial studies with model systems showed that the wear rates were quantitatively related to amounts of unreacted ZDDP as determined by peroxy radical titration: in other words, the quantity of ZDDP used in an antioxidant capacity was not available for the antiwear function. Interaction of peroxy radicals with ZDOP was followed by the extent of decay of the Infrared (IR) $P=S$ absorbance peak, which reached a value of about $40 \%$ of its original value as the ZDDP antioxidant capacity approached zero. Their results suggest that twothirds of the $P=S$ groups present in the ZDDP molecule are converted to other functional groups upon reaction with the three peroxy radicals required for complete conversion to nonreactive products at laboratory temperatures. Involvement of the sulfur atom in the reaction with peroxy radicals is consistent with electron spin resonance (ESR) data on copper dithiocarbamate, which has a molecular structure analogous to ZODP.

Ajed engine oil from fleet tests also exhibited greater $P=S$ absorbance loss, tecaying to a value of $20 \%$ when the ZDDP antioxidant capacity was depleted.

Another interesting result was obtained when willermet, et al., discovered that ZJDP retarded the oxidation decay of a hindered phenol antioxidant $(2,6$, di-t-butyl-4 methyl phenol) instead of vice versa. This result suggests that various secondary reactions of free radicals and products reduced from initial steps of the ZDDP reaction. Further, they postulated that the initial product from the hindered phenol is a moderately stable free radical which could possibly interact with ZODP and/or its products and regenerate the initial hindered phenol. 
Synergistic antioxidant behavior has also beer noted between sulfurphosphorous compounds and amines, as well as amines and phenols (particularly tri- and tetrahydroxyT-benzophenones). ${ }^{(65)}$ None of the combinations have shown the exceptional synergism of the amines and alkali metal salt compounds, $(65,66)$ A discussion of the importance of understanding this amine-alkali synergistic mechanism for high-temperature synthetic lubricants was presented in an earlier report. (a)

(a) Fehrenbacher, L. L. 1984. Identification of Tribological Research and Development Needs for Lubrication of Advanced Heat Engines. Progress Report. ORNL Order No. 86X-479864, Technology Assessment and Transfer, Inc., Gambrills, Maryland. 


\section{REFERENCES}

1. Bryzik, W. and R. Kamo, 1983. TACOM/Cummins Adiabatic Engine Program. SAE Paper 830314, Society of Automotive Engineers (SAE), Warrendale, Pennsylvania.

2. Dobbs, H. and W. Bryzik. 1982. "The Adiabatic Engine Revolution." Armor, Jan./Feb., 1982, pp. 16-21.

3. Crase, L., et a1. Dec. 1981. Compound Cycle Turbofan Engine Phase II-Single Cylinder Engine Final Test Report. AFWAL-TR-81-2123, AFWAL/POTA, Wright-patterson Air Force Base, Ohio.

4. Glance, P. and R. Munt. 1983. Engine Research, Development and Acquisition Strategy for U.S. Army Ground Vehicles. SAE Paper 830674 , Society of Automotive Engineers (SAE), Warrendale, Pennsylvania.

5. Toyama, K., et al. 1983. Heat Insulated Turbocompound Engine. SAE Paper 831345, Society of Automotive Engineers (SAE), Warrendale, Pennsylvania.

6. "The Light-Duty Diesel of the Future." 1983. Automotive Engineering, Oct. 1983, pp. 83-86.

7. Johnson, D. R. 1984. Ceramic Technology For Advanced Heat Engines Project: Semiannual progress Report, October 1983 - March 1984. ORNL/TM94 $\overline{6} 6$, Oak Ridge National Laboratory, Oak Ridge, Tennessee.

8. Society of Automotive Engineers (SAE). September 1981. Diesel Engine 0il Consumption. SAE SP-494, SAE, Warrendale, Pennsylvania.

9. Staron, 3. and P. Willermet. 1983. An Analysis of Valve Train Friction in Terms of Lubrication Principles. SAE Paper 830165 , Society of Automotive Engineers (SAE), Warrendale, Pennsylvania.

10. McGeehan, J. 1979. A Survey of the Mechanical Design Parameters Affecting Engine 0il Consumption. SAE Paper 790864, Society of Automotive Engineers (SAE), WarrendaTe, Pennsylvanía.

11. Reipert, P. and R. Buchta. 1981. New Design Methods for Pistons. SAE Paper 810933, Society of Automotive Engineers (SAE), Warrendale, Pennsylvania.

12. E1lerman, J., et al. 1981. 0i1 Consumption and Blowby of Truck-Diesel Engines--Test Bench Results. SAE Paper 810937, Society of Automotive Ergineers (SAE), WarrendaTe, Pennsylvania.

13. Munro, R. 1981. Blowby in Relation to Piston and Ring Features. SAE Paper 810932, Society of Automotive Engineers (SAE), Warrendale, Pennsylvania. 
14. Furuhama, S., et a1. 1981. An Increase of Engine 0il Consumption at High Temperature of Piston Cylinder. SAE Paper 810976, Society of Automotive Engineers (SAE), Warrendale, Pennsylvania.

15. Dueck, G. and B. Newman. 1981. Piston Ring Development--Trends in Europe Off-Highway Applications. SAE Paper 810934, Society of Automotive Engîneers (SAE), Warrendale, Pennsylvania.

16. Furuhama, S., et al. 1983. "Measurement of Piston Ring 0il Film Thickness in an Operating Engine." ASLE Trans. 25(3):305-332.

17. Moore, S. and G. Hamilton. 1974. "Comparison Between Measured and Calculated Thickness of the 0il Film Lubricating Piston Ring." IME 188(20).

18. Furuhama, S., et al. 1981. Effect of Piston and Piston Ring Designs on the Piston Friction Forces in Diesel Engines. SAE Paper 810977, Society of Automotive Engineers (SAE), Warrendale, Pennsylvania.

19. Li, D., et al. 1983. "An Automotive Piston Lubrication Model." ASLE Trans. 26(2):151-160.

20. Caterpillar Tractor Company. 1980. "Questions and Answers About Rings and Pistons." PEDP 8022, Question and Answer Booklet. Caterpillar Tractor Company, Peoria, ITTinois.

21. Curtis, J. 1981. Piston Ring Dynamics and Its Influence on Power Cylinder Performance. SAE Paper 810935, Soclety of Automotive Engineers (SAE), Warrendale, Pennsylvania.

22. McGeehan, J. 1983. Effect of Piston Deposits, Fuel Sulfur, and Lubricant Viscosity on Diesel Engine of Consumption and Cylinder Pore Polishing. SAE Paper 831721, Society of Automotive Engineers (SAE), Warrendale, Pennsylvania.

23. Clevenger, J. and I. Rozalsky. 1980. Influence of 0il Drain Period on Connecting Rod Bearings in Linehaul Diesel Truck Engines. SAE Paper 801369 , Society of Automotive Engineers (SALE), WarrendaTe, Pennsylvania.

24. Murray, D., et at. 1982. The Effect of Basestock Composition on Lubricant Performance. SAE Paper $82123 \overline{6}$, Society of Automotive Engineers (SAE), WarrendaTe, Pennsylvania.

25. Hsu, S., et al. Dec. 1982. Relationship Between Lubricating Basestock Composition and the Effects of Additives on Oxidation Stability. SAE Paper 821237, Society of Automotive Engineers (SAE), Warrendale, Pennsylvania.

26. Cashmore, K. 1982. Hydrotreated Lube 0il Base Stocks. SAE Paper 821235, Society of Automotive Engineers (SAE), Warrendale, Pennsylvania. 
27. Society of Automotive Engineers (SAE). Oct. 1980. "Engines, Fuels and Lubricants--A Perspective of the Future." SP-471, SAE, Warrendale, Pennsylvania.

28. Society of Automotive Engineers (SAE). 1981. "Synthetic Automotive Engine 0ils." Progress in Technology Series No. 22, SAE PT-22, SAE, Warrendale, Pennsylvania.

29. Raymond, L. 1980. Today's Fuels and Lubricants and How They Got That Way. SAE Paper 801341, Society of Automotive Engineers (SAE), Warrendale, Pennsylvania.

30. Cartwright, S, and L. Carey. 1980. Control of Engine 0il Acidity. SAE Paper 801366, Society of Automotive Engineers (SAE), Warrendale, Pennsylvania.

31. Davydov, P., I. Sibarova and 0. Nikiforov. 1983. Ways to Increase Motor 0il Quality for Supercharged Diesel Engines. DTIC \#ADB077654, U.S. Army Science and Technology Center, Washington, D.C.

32. Kuliev., A. May 1974, Chemistry and Technology of 0il and Fuel Additives. NTIS AD-78249, National Technical Information Service (NTIS), Springfield, Virginia.

33. Beynon, L. August 1973. A Literature Review of Investigation in the Activity of Phosphorous Containing Load Carrying Additives. NTIS \#ADAO17386, National Technical Information Service (NIS), Springfield, Virginia.

34. Rounds, F. 1981. "Some Effects of Amines on Zinc Dialkyldithiophosphate Antiwear Performance as Measured in 4-Ball Wear Tests." ASLE Trans. $24(4): 421-440$.

35. Hsu, S and R. Lin, 1983. Interactions of Additives and Lubricating Base 0ils. SAE Paper 831683, Society of Automotive Engineers (SAE), Warrendale, Pennsylvania.

36. Rounds, F. 1972. "Influence of Steel Composition on Additive Performance." ASLE Trans. 15(1):54-64.

37. Brainard, W. and J. Ferrante. April 1983. "Effect of 0xygen Concentration in ZOP Containing 0ils on Surface Composition and Wear." NASA TM 83000 , National Technical Information Service (NTIS), Springfield, Virginia.

38. Braithwaite, E, and A. Greene. 1978. "A Critical Analysis of the Performance of Molybdenum Compounds in Motor 0ils." Wear 46(2):405-432.

39. Naman, T. 1980. Automotive Fuel Economy--Potential Improvement Through Selected Engine and Gear Lubricants. SAE Paper 800438, Society of Automotive Engineers (SAE), Warrentale, Pennsylvania. 
40. Bennington, J., et al. 1975. Stable Colloid Additives for Engine 0ils-Potential Improvement in Fuel Economy. SAE Paper 750677 , Society of Automotive Engineers (SAE), Warrendate, Pennsylvania.

41. Reick, F. May 1981. Energy-Saving Lubricants Containing Colloidal PTFE. ASLE Preprint 81-AM-50-2, American Society of Lubrication Engineers, Park Ridge, Illinois.

42. Adams, J. and D. Bodfrey. May 1980. Borate Gear Lubricant--EP Film Analysis and Performance. ASLE Preprint 80-AM-3D-2, American Society of Lubrication Engineers, Park Ridge, Illinois.

43. Adams, J., et a1. 1981. The Effect of Gear ubricant on Fuel Economy as Measured in a Line Haul Truck fleet. SAE Paper 810179, Society of Automotive Engineers (SAE), Warrendale, Pennsylvania.

44. Gansheimer, J. and R. Holinski. April 1973. "Molybdenum Disulfide in 0ils and Greases Under Boundary Conditions." ASME Trans., April 1973, pp. 242-248.

45. Bartz, W. 1977. "Influence of Extreme Pressure and Detergent-Dispersant Additives on the Lubricating Effectiveness of Molybdenum Disulfide." Lubrication Engineering 33:139-145.

46. Bartz, W. and J. Oppelt. 1980. "Lubricating Effectiveness of 0il Soluble Additives and Molybdenum Disulfide Dispersed in Mineral Dil." Lubrication Engineering 35:579-585.

47. Bartz, W. 1971. "Solid Lubricant Additives-..Effect of Concentration and Other Additives on Antiwear Performance." Wear 17:421-432.

48. Thorp, J. 1973. "The Mechanism of Lubrication by Molybdenum Disulphide Dispersed in $0 i 1$ and the Effect of a Zinc Dialkyldithiophosphate Additive." Wear 23:63-70.

49. Keiser, R. and J. Castor. Dec. 1981. Compound Cycle Turbofan Engine Phase II, Materials Report. AFWAL-TR-81-2141, AFWAL/POTA, WrightPatterson Air Force Base, ohio.

50. Frome, C. Nov. 1983. High-Temperature Lubricants for Minimum-Cooled Diese1. Engines. USAFLRL Interim Report 171, Southwest Research Institute, San Antonio, Texas.

51. Cameron, C. and D. Ferriss, 1973. "New Alloy Fights Corrosion and Wear." Machine Design, August 9, 1973.

52. Strong, D. H. U.S. Patent 3.052,954, "Method of Using a Material as a Rolling Contact Bearing." September 11, 1962. 
53. Shimauchi, T., et al. 1984. Tribology at High Temperatures for Uncooled Heat Insulated Engine. SAE Paper 840429, Society of Automotive Engineers (SAE), Warrendale, Pennsylvania.

54. Walson, R., et al. 1984. Performance of a Ceramic Rotor in a Cumnins T46 Turbocharger. SAE Paper 840014, Society of Automotive Engineers (SAE), WarrendaTe, Pennsylvania.

55. Sakamoto, T., et al. 1982. "The Reaction Layer Formed on Steel by Additives Based on Sulphur and Phosphorous Compounds Under Conditions of Boundary Lubrication." Wear 77:139-157.

56. Forbes, E. S., et al. 1969. "Tribology Convention 1969, Paper 6." (See Reference 33.)

57. Dorinson, A. 1979. "The Antiwear Action of Zinc Di-n-Butyl Phosphate." ASLE Trans, 22(2):190-192.

58. Barcroft, F. and S. Daniel. 1965. J. Basic Eng. 870:761.

59. Loeser, E., et al. 1958. ASLE Trans. 1:329.

60. Loeser, E., et al. 1960. ASLE Trans. 2:199.

61. Willermet, P., et a1. 1980. ASLE Trans. 23(3):217.

62. Willermet, P., et al. 1980. ASLE Trans. 23(3):225.

63. Chao, T. and M. Kjonaas. 1982. "Some Synergistic Antioxidants for Synthetic Lubricants." Symposium on Synthetic and Petroleum-Based Lubricants, American Chemical Society Meeting, March 28 - April 2, 1982 , La's Vegas, Nevada.

64. Chao, T., et al. 1984. "Some Synergistic Antioxidants for Synthetic Lubricants." Ind. Eng. Chem. Prod. Res. Dev. 23:21-27. 
No. of

Copies

OFFSITE

12 T. Levinson

U.3. Department of Energy

Forrestal Building CE-142

Washington, D.C. 20585

J. J. Eberhardt

U.S. Department of Energy

Forrestal Building

Mail Stop 6B025

Washington, D.C. 20585

30 OOE Technical Information

Center

\section{A. Anderson \\ Multi-Arc Vacuum Systems Inc. \\ 261 East 5th Avenue \\ St. Paul, MN 55101 \\ C. Albertson \\ Borg-Warner Corporation \\ 1200 South Wolf Road \\ Des Plaines, It 60018}
A. Becker
Alumina, Chem. \& Ceramics Division
Alcoa Research Laboratories
A1 cod Center, PA 15069
P. N. Blumberg
Integral Technologies, Inc. 415 East Plaza Drive
Westmont, IL 60559
L. J. Brombolich
Compu-Tec Engr. Inc.
300) Chesterfield Center, 205
Chesterfield, M0 63017
W. Bryzik
IJ.5. Army TACDM
AMSTA-RGR
Warren, MI 48090

No of

Copies

D. H. Buck ley

NASA/Lewis Research Center

23-2

Cleveland, $\mathrm{OH} \quad 44135$

R. F. Bunshah

Department of Materials Science

University of California at

Los Angeles

6532 Boelter Hall

Los Angeles, CA 90024

J. A. Carpenter, Jr.

Oak Ridge National Laboratory

P0 Box $X$, Bujlding 4508

Dak Ridge, TN 37831

D. C. Classen

Caterpillar Tractor Co.

Mfg. Engr. Building $W$

600 West Washington Street

East Peoria, IL 61630

F. J. Carignan

Advanced Mechanical

Technology Inc.

141 California Street

Newton, MA 02158

D. L. Cocke

Texas A\&M University

Department of Chemistry

College Station, TX 77843-3255

H. S. Cheng

Dept. of Mechanical Engineering

Center for Engineering

Tribology

Northwestern University

Evanston, IL 60201

G. W. Clark

Oak Ridge National Laboratory

PO Box $X$, Building 4508

0ak Ridge, TN 37831 
No of

Copies

G. Chang

29615 Lincoln Road

Bay Village, $\mathrm{OH} 44140$

M. J. Cronin

Mechanical Technology, Inc. 968 Albany-Shaker Road

Latham, NY 12110

J. L. Duda

Pennsylvania State University

133 Fenske Laboratory

University Park, PA 16802

S. K. Das

Materials Laboratory

Allied Corporation

P.0. Box $1021 \mathrm{R}$

Morristown, NJ 07960

J. F. Dill

Mechanical Technology Inc.

968 Atbany-Shaker Road

Latham, NY 12110

R. L. DaSilveira

Eutectic Corp.

4040172 nd Street

Flushing, NY 11358

C. A. Ebel

High Performance Ceramics

Norton Company

1 New Bond Street

Worcester, MA 01606

R. Erickson

Battelle-Columbus Laboratory 505 King Avenue

Columbus, $\mathrm{OH}$ 43201-2693

12 L.. L. Fehrenbacher

2002 Huntwood Drive

Hunt ington Woods

Gambrills, MD 21054
No of

Copies

D. G. Flom

General Electric Company

Corporate R\&D, 4B4, K-1

P.0. Box 8

Schenectady, NY 12301

T. Fischer

Exxon Research

Clinton Township Route 22 East

Annandale, NJ 08801

P. Grayson

Eagle Picher Industries, Inc.

P.0. Box 1090

Miami, OX 74354

J. Graham

Deere and Company

Technical Center

3300 River Drive

Moline, IL 61265

S. Goguen

U.S. Department of Energy, CE 131

Mailstop $5 E 043$

Forrestal Building

1000 Independence Ave., SW

Washington, D.C. 20585

R. M. Gresham

E/M Lubricants, Inc.

P.0. Box 2200, Highway 52 N.W.

West Lafayette, IN 47906

J. Horwath

Borg-Warner Corporation

Ingersoll Research Center

1200 S. Wolf Road

Des Plaines, IL 60018

S. M. Hsu

Room A257, Building 223

Inorganic Materials Division

National Bureau of Standards

Gaithersburg, MD 20899 
No of

Copies

N. S. Hakim (RD3B)

Detroit Diesel Allison Division

36880 Ecorse Road

Romulus, MI 48174

C. R. Houska

Dept. of Materials Engineering

Virginia Polytechnic Institute

Biacksburg, VA 24061

R. A. Harmon

25 Schalren Drive

Latham, NY 12110

J. K. Hirvonen

Spire Corporation

Patriots Park

Bedford, MA 07130

10 M. Kaminsky

Argonne National Laboratory

9700 South Cas

Argonne, IL 60439

E. E. Klaus

Dept. of Chemical Engineering

Pennsylvania State University

University Park, PA 16802

R. Krutenat, 102/D217

Exxon Research and

Engineering $\mathrm{Co}$.

Florharn Park, NJ 07932

S. Khanna

Solid State Science Research Group

Jet Propulsion Laboratory

4800 Oak Grove Drive

MS 122-123

Pasadena, CA 91109

K. Ludema

University of Michigan

Dept. of Mechanical Engineering

2024 G. G. Brown

Ann Arbor, MI 48109-2125
No of

Copies

Librarian

Deere and Company

Technical Center

3300 River Drive

Moline, IL 61265-1792

F. F. Ling

Mechanical Engineering

Jonsson Engineering Center

Rensselaer Polytechnic

Institute

Troy, NY 12181

H. LeKhac

DHR Inc.

6849 01d Dominion Drive

McLean, VA 22101

H. E. McCormick

Director of Engineering

Ramsey Piston Ring Division

TRW Automotive Products, Inc.

1233 Manchester Road

Manchester, MO 63011

C. Mecklenburg

AFWAL/MLBT

Wright Patterson AFB

Dayton, $\mathrm{OH}$ 45433-6533

J. McCOOI

SKF Industries

1100 First Avenue

King of Prussia, PA 19406

R. W. Meyerhoff

Union Carbide Corporation

Coatings Service

1500 Polco Street

Indianapolis, IN 46224

J. R. Mullaly

Pratt \& Whitney Aircraft

P.0. Box 2691

MS 707-28

West Palm Beach, FL 33402 
No of

Copies

P. Madden

SKF Industries

1100 First Avenue

King of Prussia, PA 19506

M. B. Peterson

Wear Sciences, Inc.

925 Mallard Circle

Arnold, MD 21012

0. Pinkus

Mechanical Technology Ine.

968 Albany-Shaker Road

Latham, NY 12110

T. F. J. Quinn

Tribology and Rheology Laboratory

School of Mechanical

Engineering

Georgia Institute of Technology

AtTanta, GA 30332

R. C. Rosenberg

General Motors Research Laboratory

Fiuid Mechanics 0epartment

Warren, MI 48090

D. A. Rigney

The Onio State University

Dept. of Metallurgical Engineering

141A Fontana Laboratories

116 West 19th Avenue

Columbus, $\mathrm{OH}$ 43210-1179

A. W. Ruff

Nationa 1 Bureau of Standards

Metallurgy Division

Room B266-Materials Building

Gaithersburg, MD 20899

W. D. Sproul

Borg-Warner Corporation

1200 South Wolf Road

Des Plaines, IL 60018
No of

Copies

P. Sutor

Midwest Research Institute

425 Volker Boulevard

Kansas City, MO 64110

L. B. Sibley

Tribology Consultants, Inc. 504 Foxwood Lane

Paoli, PA 19301

A. C. Schaffhauser

Oak Ridge National Laboratory

P.0. Box X

Oak Ridge, TN 37831

I. L. Singer

Naval Research Laboratory

Code 6170

Washington, D.C. 20375

G. L. Starr, Manager

Metallurgical Engineering

Cummins Engine Technical Center

Box 3005

Columbus, IN 47202-3005

R. Slone 50165

Cummins Engine Technical Center Box 3305

Columbus, in 47202-3005

T. C. Spalvins

NASA/Lewis Research Center

MS 23-2

Cleveland, $\mathrm{OH} 44135$

M. Shaw

Arizona State University

ECG 247, Mechanical Engineering

Tempe, AZ 85287

P. Swanson

John Deere Company

Technical Center

3300 River Drive

Moline, IL 61265 
No of

Copies

L. D. Wedeven

SKF Industries, Inc.

1130 First Avenue

King of Prussia, PA 19406

R. Ted Wimber

Deere and Company

Technical Center

3300 River Drive

Moline, IL 61265-2792

D. F. Wilcock, President

Tribolock, Inc.

1949 Hexham Road

Schenectady, NY 12309

W. 0. Winer

Tribology and Rheology Laboratory

School of Mechanical

Engineering

Georgia Institute of Technology

Atlanta, GA 30332

D. Kuhlman-Wilsdorf

University of Virginia

Physics 0epartment

Mciormick Road

Charlottesville, va 22901

W. H. Winnard

Ba:telle Memorial Institute

2030 M. Street NW

Washington, D.C. 20036

C. S. Yust

Metals and Ceramics Division

Oak Ridge National Laboratory

P. O. Box $X$

Oak Ridge, TN 37831

T. M. Yonushonis

Curnmins Engine

Mai] Code 50183, Box 3005

Columbus, IN 47202-3005
No of

Copies

M. Zlotnick

141 East 88th Street

New York, NY 10028

C. A. Zanis

Department of the Navy

Naval Sea Systems Command

Research and Development office

Washington, 0.C. 20362

FOREIGN COUNTRIES

Dr. Jochen P. Biersack

Hahn-Meitner-Institut

Glienicker Strabe 100

1000 Berlin 39

West Germany

Dr. Erich Bergmann

Baizers Aktiengesellschaft

FL-9496 Balzers

Furstentum, Liechtenstein

Professor Dr. H. Czichos

Federal Institute for Materials

Research and Testing

Unter den Eichen 87

D-1000 Berlin 45

West Germany

Or. Geoff Dearnaley

Nuclear Physics Division

Building $\mathrm{H} 8$

AERE, Harwell

Didcot, Oxfordshire

United Kingdom OX 11 ORA

Or. Hans E. Hintermann

Laboratoire Suisse de

Recherches Horlogeves

$\mathrm{CH}-2000$ Neuchatel

Switzerland 
No of

Copies

Dr. Richard Horton, Manager Energy Conservation Technology Centre

Engineering Sciences Division

B151 Harwell Laboratory

Oxfordshire 0X 11 ORA

England

Dr. Boris Navinsek

Jozef Stefan Institute

61001 Ljubljana

Jamova 39

Yugoslavia

Prof. Dr. ir. J. Roos

Katholieke Universiteit Leuven

Department Metaalkunde

de Croylaan 2

B-3030 Leuven (heverlee)

Belgium

Dr. S. Veprek

Anorganisch-Chemisches

Institut der Universitat Zurich

Winterthurerstrasse 190

8057 Zurich

Switzerland
No. of

Copies

ONSITE

DOE Richland Operations office

H. E. Ransom/D. R. Segna

12 Pacific Northwest Laboratory

D. L. Brenchley

C. H. Imhoff

D. C. Kuick

J. A. Russell

M. T. Thomas

Publishing Coordination MH (2)

Technical Information (5) 